\title{
Chemical, molecular, and single cell analysis reveal chondroitin sulfate proteoglycan aberrancy in
}

\section{fibrolamellar carcinoma}

Adam B. Francisco ${ }^{1, *}$, Jine $\mathrm{Li}^{2,4 *}$, Alaa R. Farghli ${ }^{1}$, Matt Kanke ${ }^{1}$, Bo Shui ${ }^{1}$, Paul D. Soloway ${ }^{1}$, Zhangjie Wang ${ }^{3}$,

Lola M. Reid ${ }^{4}$, Jian Liü,\#, and Praveen Sethupathy,"\#

${ }^{1}$ Department of Biomedical Sciences, College of Veterinary Medicine, Cornell University, Ithaca, NY 14853, USA

${ }^{2}$ Division of Chemical Biology and Medicinal Chemistry, Eshelman School of Pharmacy, University of North Carolina, Chapel Hill, NC 27599, USA

${ }^{3}$ State Key Laboratory of Microbial Resources, Institute of Microbiology, Chinese Academy of Sciences, Beijing, China

${ }^{4}$ Department of Cell Biology and Physiology, School of Medicine, University of North Carolina, Chapel Hill, NC 27599, USA

${ }^{*}$ These authors contributed equally.

\#These authors contributed equally.

\section{$\underline{\text { Running Title }}$}

Proteoglycan aberrancy in fibrolamellar carcinoma

\section{Keywords}

Fibrolamellar carcinoma, single-cell, ATAC, glycosaminoglycan, proteoglycan, tumor microenvironment

\section{Financial Support}

This study was made possible by funding from the Fibrolamellar Cancer Foundation (awarded to P.S.)

\section{Correspondence}

Praveen Sethupathy, PhD

Department of Biomedical Sciences

College of Veterinary Medicine 
Cornell University

Veterinary Research Tower T7 006D

Ithaca, NY 14853

Email: pr46@cornell.edu

Telephone: 607-253-4347

Fax: 607-253-4447

\section{Competing Interests}

The authors declare no competing interests.

\section{Manuscript Notes}

Word count (including references): 11,250

Main figures: 7 , Supplemental figures: 5

\section{$\underline{\text { Abstract }}$}

Fibrolamellar carcinoma (FLC) is an aggressive liver cancer with no effective therapeutic options. The extracellular environment of FLC tumors is poorly characterized and may contribute to cancer growth and/or metastasis. To bridge this knowledge gap, we assessed pathways relevant to proteoglycans, a major component of the extracellular matrix. We first analyzed gene expression data from FLC and non-malignant liver tissue ( $n=27)$ to identify changes in glycosaminoglycan (GAG) biosynthesis pathways and found that genes associated with production of chondroitin sulfate, but not other GAGs, are significantly increased by 8fold. We then implemented a novel LC-MS/MS based method to quantify the abundance of different types of GAGs in patient tumors $(n=16)$ and found that chondroitin sulfate is significantly more abundant in FLC tumors by 6-fold. Upon further analysis of GAG-associated proteins we found that versican (VCAN) expression is significantly up-regulated at the mRNA and protein levels, the latter of which was validated by immunohistochemistry. Finally, we performed single-cell assay for transposon-accessible chromatinsequencing on FLC tumors $(n=3)$, which revealed for the first time the different cell types in FLC tumors and also showed that VCAN is likely produced not only from FLC tumor epithelial cells but also activated stellate cells. Our results reveal a pathologic aberrancy in chondroitin (but not heparan) sulfate proteoglycans in FLC and highlight a potential role for activated stellate cells. 


\section{Significance}

This study leverages a multi-disciplinary approach, including state-of-the-art chemical analyses and cutting-edge single-cell genomic technologies, to identify for the first time a marked chondroitin sulfate aberrancy in fibrolamellar carcinoma (FLC) that could open novel therapeutic avenues in the future.

\section{Introduction}

Fibrolamellar carcinoma (FLC) is a rare form of liver cancer that predominantly afflicts adolescents and young adults ${ }^{(1,2)}$. Patients with FLC lack standard of care, leaving surgical resection as the primary therapeutic option. Unfortunately, often patients are not eligible for surgery due to metastasis at the time of diagnosis.

Paramount to improving patient care is the need to identify molecular pathways that are critical to FLC tumor survival and growth.

FLC is characterized by a $\sim 400 \mathrm{~kb}$ heterozygous deletion on chromosome 19 , which creates the DNAJB1-PRKACA (DP) fusion kinase ${ }^{(3)}$. DP is found in more than $80 \%$ of FLC patients ${ }^{(4)}$ and genome-scale analyses have identified widespread alterations in chromatin activity ${ }^{(5)}$ leading to dysregulated genes and noncoding RNAs ${ }^{(6,7)}$, including microRNAs ${ }^{(8,9)}$. These studies have highlighted increased activation of pro-growth pathways ${ }^{(5)}$ and increased resistance to cell death ${ }^{(10)}$.

A characteristic histologic feature of FLC tumors is the presence of thick, fibrous bands ${ }^{(11)}$. This observation brings into focus the likely importance of the extracellular environment to FLC tumor growth and metastasis, as is the case in many other aggressive cancers as well. Surprisingly though, extracellular matrix composition, including proteoglycans in the pericellular tumor microenvironment, has not been investigated in FLC.

Altered extracellular matrix composition has been identified in numerous cancer types ${ }^{(12-14)}$. These changes include increased deposition of collagens and fibrillins, matrix remodeling enzymes such as matrix metalloproteinases, and elevated abundance of glycosaminoglycans (GAGs) and associated proteoglycans (PGs). GAGs and PGs are of notable interest as they contribute to both the structure and mechanics of the tumor stroma and enhance extracellular signaling by sequestering and concentrating soluble growth factors. 
Through these mechanisms, GAGs and PGs play an important role in the processes of angiogenesis, proliferation, and migration ultimately promoting tumor metastasis ${ }^{(15-18)}$.

GAGs are polysaccharides of varying lengths comprised of repeating disaccharide units ${ }^{(19)}$. The most common GAGs are hyaluronic acid (HA), heparan sulfate (HS), and chondroitin sulfate (CS). HA chains bind to many components of the extracellular matrix, including collagen. Unlike HA, HS and CS, which differ in disaccharide composition and glycosidic bond linkage patterns, are conjugated to specific core proteins, which are then reclassified as proteoglycans ${ }^{(20,21)}$. PGs share many general characteristics, including domains that bind soluble growth factors and stimulate cellular receptors. Additionally, individual PGs can vary in length, and the core proteins can be alternatively spliced, all of which can have affect physiological processes ${ }^{(22,23) .}$ Finally, polysaccharides can undergo extensive sulfation, the effects of which are essential for these functions (24).

Examples of PGs that have been well-studied in the cancer context include HS proteoglycan, perlecan (HSPG2), and the CS proteoglycan, versican (VCAN). HSPG2 binds multiple fibroblast growth factors (FGFs) and the vascular and endothelial growth factor (VEGF), and is significantly upregulated in many cancers, including melanoma ${ }^{(25,26)}$, breast carcinomas ${ }^{(27,28)}$, and glioblastoma ${ }^{(29)}$. Mouse xenograft models of these cancers in which HSPG2 expression has been ablated show reduced tumor volume ${ }^{(16,28,30)}$. Through similar mechanisms, VCAN is known to promote the metastasis of prostate and breast cancer by promoting plateletderived growth factor (PDGFA) signaling, interacting with selectins, a family of cellular adhesion molecules, and promoting EGFR signaling ${ }^{(31)}$. The role of proteoglycans in liver cancer, particularly hepatocellular carcinoma (HCC), has been studied extensively and multiple HS proteoglycans have been identified as important contributors to tumor progression ${ }^{(32)}$. However, it is unknown whether these mechanisms are shared with FLC.

In this study, we sought to bridge the important knowledge gap on GAGs/PGs in FLC. Specifically, through the combined use of RNA-seq, GAG disaccharide quantification by LC-MS/MS, and single-cell assay for transposase-accessible chromatin (SCATAC), we quantified HS and CS abundance and interrogated the activity of PGs at single-cell resolution in FLC and non-malignant liver samples. These studies confirmed that FLC tumor cells preferentially produce chondroitin sulfate and that VCAN is one of the primary proteoglycans 
in FLC. Moreover, we demonstrated that there is more ATAC signal at the VCAN locus in activated hepatic stellate cells than any other cell type.

\section{Materials and Methods}

\section{Human Samples}

Informed consent was obtained from all individuals. Tumor and adjacent non-malignant liver samples were collected from patients with FLC by surgeons in accordance with the Institutional Review Board protocols 1802007780, 1811008421 (Cornell University) and 33970/1 (Fibrolamellar Cancer Foundation) and provided by the Fibrolamellar Cancer Foundation. Patients included male and female subjects and some samples were collected from the same patient. All samples were de-identified before shipment to Cornell.

\section{PolyA+ RNA library preparation and sequencing}

The 27 RNA-seq datasets analyzed in this study were generated previously ${ }^{(5) .}$ Frozen tumors underwent physical dissociation using a polytron PT1200 E homogenizer (Thomas Scientific, Swedesboro, NJ) and total RNA was isolated using the Total RNA Purification Kit (Norgen Biotek, Thorold, ON, Canada) per manufacturer's instructions. RNA purity was quantified with the Nanodrop 2000 (Thermo Fisher Scientific, Waltham, MA) or Nanodrop One and RNA integrity was quantified with the Agilent 4200 Tapestation (Agilent Technologies, Santa Clara, CA). Libraries were prepared by the Cornell Transcriptional Regulation and Expression (TREx) Facility using the NEBNext Ultra II Directional RNA kit (New England Biolabs, E7760, Ipswich, MA). Sequencing was performed at the Biotechnology Research Center at Cornell University on the NextSeq500 (Illumina, San Diego, CA).

\section{Quantitative PCR}

Reverse Transcription was performed using the High-Capacity RNA-to-cDNA Kit (Thermo Fisher Scientific). Gene and microRNA expression were quantified with TaqMan Expression assays on a CFX96 Touch RealTime System thermocycler (Bio-Rad, Hercules, CA). Gene expression assays were normalized to the expression of RPS9. Individual gene assay IDs: CSGALNACT1 Hs00218054_m1, VCAN Hs0017642_m1, 
CHST3 Hs01000045_m1, CHST11 Hs00218229_m1, RPS9 Hs02339424_m1. Expression values reported are averaged across at least three $(n=3)$ biological replicates unless otherwise stated in the main text.

\section{Immunoblot analysis}

FLC and NML tissues were lysed in RIPA buffer containing Halt protease and phosphatase inhibitors (Thermo Fisher Scientific) at $4^{\circ} \mathrm{C}$. Lysates were incubated for 30 minutes and centrifuged at $14,000 \mathrm{Xg}$ for 10 minutes at $4^{\circ} \mathrm{C}$. Total protein in the supernatant was quantified using the BCA Protein Assay Kit (Thermo Fisher Scientific). Samples were denatured in NuPAGE LDS Sample Buffer (Thermo Fisher Scientific) containing 5\% $\beta$-Mercaptoethanol for 10 minutes at $70^{\circ} \mathrm{C}$ and loaded to a $12 \%$ SDS-polyacrylamide gel. After electrophoresis, samples were transferred to polyvinylidene difluoride membrane and blocked in Tris buffered saline containing 0.5\% TWEEN20 (TBST) and 3\% bovine serum albumin for 1 hour at room temperature. Membranes were probed for anti-versican GAG $\beta$ (1:1000 dilution, rabbit source, Millipore AB1033) or anti-vinculin (1:10000 dilution, mouse source VLN01, Thermo Fischer Scientific MA5-11690) overnight at $4^{\circ} \mathrm{C}$ and then incubated with goat anti-rabbit HRP linked IgG (1:10000, Cell signaling). Membranes were visualized using a ChemiDoc MP (Bio-Rad, Hercules, CA).

\section{Immunohistofluorescence analysis}

FLC and NML tissues were formalin-fixed at the time of surgery, dehydrated in ethanol, and paraffin embedded for tissue sectioning onto glass slides. Tissue was deparaffinized by two incubations in xylene, followed by one incubation in 1:1 xylene:ethanol (three minutes per incubation). Tissue was rehydrated by incubation in decreasing concentrations of ethanol: twice in 100\%, 95\%, 75\%, and 50\% (three minutes per incubation). Finally, tissue was incubated in a flushing water bath for fifteen minutes. Tissue was then incubated in methanol for twenty seconds, followed by equilibration in PBS for at least two minutes. Antigen retrieval was performed by incubating for twenty minutes in preheated $10 \mathrm{mM}$ sodium citrate $(\mathrm{pH} 6.0)$ buffer containing $0.05 \%$ tween-20 (weight/volume) submerged in a boiling water bath. Tissue in citrate buffer was then removed for the bath and allowed to cool for thirty minutes. Tissue was then incubated in PBS containing $0.03 \%$ tween-20 for two minutes followed by blocking in $10 \%$ normal goat serum diluted in PBS containing $0.03 \%$ tween-20 for one 
hour. Tissue was then washed in PBS containing $0.03 \%$ tween-20 for two minutes following overnight incubation at $4^{\circ} \mathrm{C}$ with anti-versican GAG $\beta$ (1:100 dilution, rabbit source, Millipore AB1033). Tissue was then washed three times in PBS containing $0.03 \%$ tween-20 for fifteen minutes followed by secondary antibody staining for one hour at room temperature (anti-rabbit Alexafluor 488, 1:1000 dilution, goat source, Thermo Fischer Scientific A32731). Tissue was washed three times in PBS containing $0.03 \%$ tween-20 for fifteen minutes followed by a five-minute incubation with DAPI to counterstain cell nuclei. Excess DAPI was washed out with two incubations in PBS for ten minutes each. Tissue was then dried briefly, a small volume VectaMount (Vector Labs, Burlingame, CA, H-5000) of was added, and a coverslip was mounted. Images were acquired on an Olympus DP80 microscope with the CellSense Dimension software package. All images received equal brightness balancing with ImageJ software.

\section{Single cell assay for transposon-accessible chromatin}

\section{$\underline{\text { Homogenization }}$}

We generated 6 libraries from 70 milligrams of non-malignant liver (NML), primary FLC tumor, and metastatic FLC tumor either with or without collagenase treatment. Tissue was first chopped over dry ice and then dissociated with a Dounce homogenizer using a loose pestle in $2 \mathrm{~mL}$ of homogenization buffer (1X HB: 320 $\mathrm{mM}$ sucrose, $30 \mathrm{mM}$ calcium chloride, $18 \mathrm{mM}$ magnesium acetate, $60 \mathrm{mM}$ tris(hydroxymethy)aminomethane (TRIS) pH 7.8, $0.1 \mathrm{mM}$ ethylenediaminetetraacetic acid (EDTA), $0.1 \% \mathrm{v} / \mathrm{v}$ nonyl phenopolyethoxylethanol-40 (NP40), $0.1 \mathrm{mM}$ phenylmethylsulfonyl fluoride (PMSF), $1 \mathrm{mM} \beta$-mercaptoethanol, $10 \mathrm{mg} / \mathrm{mL}$ collagenase IV) for 15-20 strokes. The homogenate was incubated for 3 minutes on ice and then mixed by pipetting 10 times. 6 mL of ATAC-RSB wash buffer (1X ATAC-RSB: $10 \mathrm{mM}$ TRIS pH 7.4, $10 \mathrm{mM}$ sodium chloride, $3 \mathrm{mM}$ magnesium chloride) was added and the homogenate was mixed by pipetting 5 times, incubated on ice for 5 min, and centrifuged at $500 \times \mathrm{g}$ for $10 \mathrm{~min}$ at $4^{\circ} \mathrm{C}$, and the supernatant was removed without disrupting pellet. The nuclei were resuspended in $2 \mathrm{~mL}$ of ATAC-RSB wash buffer and then dissociated with a Dounce homogenizer using a loose pestle for 5 strokes, and then a tight pestle for 15-20 strokes, and incubated on ice for $3 \mathrm{~min}$. Then $6 \mathrm{~mL}$ of ATAC-RSB wash buffer was added mixed by pipetting- 10 times and incubated on ice for 3-5 minutes. The suspension was passed through $70 \mu \mathrm{m}$ Cell Strainer, centrifuged at $500 \times \mathrm{g}$ for 10 minutes 
at $4^{\circ} \mathrm{C}$, and the supernatant was removed. The pellet was resuspended in $1 \mathrm{~mL}$ OMNI-ATAC buffer (1X OMNI-

ATAC: $12.5 \mathrm{mM}$ TRIS pH 7.4, $6.25 \mathrm{mM}$ magnesium chloride, 1.25\% v/v dimethylformamide (DMF), 0.125\% v/v

Tween-20, 0.01\% v/v digitonin in 0.4X phosphate-buffered saline (PBS)) and passed through a 30 $\mu \mathrm{m}$ Cell

Strainer. A $10 \mu \mathrm{L}$ aliquot of nuclei was quantified by double staining with 4',6-diamidino-2-phenylindole (DAPI)

(10 $\mu \mathrm{L}$ of a $100 \mathrm{ug} / \mathrm{mL}$ solution incubated $5-10$ minutes at room temperature) and trypan blue ( $10 \mu \mathrm{L}$ of $0.4 \%$

v/v solution incubated 5 minutes at room temperature). The final nuclei count was adjusted to 300,000

nuclei/mL.

$\underline{\text { Tn5 storage and transposome assembly }}$

Tn5 transposase $(4 \mu \mathrm{M})$ is stored at $-80^{\circ} \mathrm{C}$ and diluted for usage by adding 0.8 volume of $100 \%$ glycerol. The transposome is assembled by adding 0.11 volume of Tn5 adaptors ( $25 \mu \mathrm{M}$ stock solution) to Tn5 stock solution. The mixture was incubated at room temperature for $12-24 \mathrm{~h}$. The transposome $(\sim 2 \mu \mathrm{M})$ can be used directly or stored at $-20^{\circ} \mathrm{C}$.

\section{$\underline{\text { Tagmentation and Sample Processing }}$}

Nuclei suspension $(8 \mu \mathrm{L}$ ) was distributed onto 96 well plates and $1 \mu \mathrm{L}$ of each i5 and i7 transposome (final concentration $400 \mathrm{nM}$ ), was added to each well, resulting in a unique barcode combination in each nucleus. The tagmentation reaction plate was incubated (30 minutes at $50^{\circ} \mathrm{C}$ ) and the reaction was terminated by adding $10 \mu \mathrm{L} 20 \mathrm{mM}$ EDTA (15 minutes at $3^{\circ} \mathrm{C}$ ). Next, $20 \mu \mathrm{L}$ of Sorting buffer (1X SB: 1X PBS, 2mM EDTA, $20 \mathrm{ng} / \mathrm{mL}$ bovine serum albumin (BSA)) was added to each well and nuclei were re-pooled into a single sample. Intact nuclei were then stained with DRAQ7 for 15 minutes (ABCam, ab109202, Waltham, MA), passed through a $30 \mu \mathrm{m}$ filter, and reisolated by fluorescent-assisted cell sorting using a FACSMelody instrument (Becton, Dickinson). A 96 well plate was preloaded with $10 \mu \mathrm{L}$ of modified sorting buffer (1X SEB: $10 \mathrm{mM}$ TRIS $\mathrm{pH} 8.0,12 \mathrm{ng} / \mathrm{uL}$ BSA, 0.05\% v/v sodium dodecyl sulfate (SDS)), 25 nuclei were distributed into each well, and incubated for 10 minutes at 55으. Nuclei were further solubilized by adding $2.5 \mu \mathrm{L}$ of $5 \% \mathrm{v} / \mathrm{v}$ Triton-X100. Libraries were amplified 15 cycles while incorporating standard Nextera (Illumina) barcodes ( $1 \mu \mathrm{L}$ of $25 \mu \mathrm{M}$ primer i5:i7 in $25 \mu \mathrm{L}$ PCR reaction per well).

$\underline{\text { PCR cleanup, Size Selection, and Sequencing }}$ 
All wells were re-pooled and purified with a MinElute PCR purification kit following the manufacturer's instructions (Qiagen, 28004) and eluted twice with $20 \mu \mathrm{L}$ of the supplied buffer. The $40 \mu \mathrm{L}$ elution was further purified and size-selected using magnetic solid phase reversible immobilization (SPRI) beads following the manufacturer's instructions (Beckman Coulter, A63880) and eluted in $20 \mu \mathrm{L}$. Libraries were prepared by the Cornell Transcriptional Regulation and Expression (TREx) Facility using the NEBNext Ultra II Directional RNA kit (New England Biolabs, E7760, Ipswich, MA). Sequencing was performed at the Biotechnology Research Center at Cornell University on the NextSeq500 (Illumina, San Diego, CA).

\section{ArchR Pipeline for single cell ATAC analysis}

\section{snATAC-seq preprocessing}

Bam files are sorted and indexed using samtools and are converted to fragment files using sinto with use_chrom "” and -barcode_regex " $\left(?<=\_\right)\left(.^{*}\right)\left(?=\_\right)$" parameters. Fragment files are then sorted and finally used to generate tabix files using tabix.

\section{snATAC-seq QC and Dimensionality reduction and clustering analysis}

The transcription start site (TSS) enrichment score and fragment number of each nucleus is calculated using ArchR v1.0.1. Nuclei with TSS enrichment score less than 3 and fragment number less than 1,000 are removed. Doublet scores were calculated with default parameters.

We preformed iterative latent semantic indexing by using the `addlterativeLSI function of ArchR. We then used the default harmony algorithm to correct for batch-effects differences and added clusters using the `addClusters` function.

\section{$\underline{\text { Identification of marker features }}$}

We identified cluster markers using the function `getMarkerFeatures` with default parameters and then applied the `addlmputeWeights` function to impute the weights of markers. We visualize marker features using the 'plotEmbedding` function. To plot browser tracks we used the `plotBrowserTrack function and arranged track rows from highest to lowest accessibility using the `useGroups` parameters.

\section{$\underline{\text { Identification of cell-types from snATAC-seq data }}$}


We used unbiased approaches to assign cell-type identity to clusters. A pairwise comparison of ArchR defined markers and scRNA-seq liver markers revealed high confidence cell-type assignments for clusters 1-3, and 5-

12. Additional GO and KEGG analyses confirmed several cluster assignments.

$\underline{\text { Plotting browser tracks }}$

Accessibility of chromatin surrounding genes of interest is plotted using the default 'plotBrowserTrack function.

\section{RNA-seq bioinformatic analysis}

Paired end RNA sequencing reads were aligned to the human genome (hg38) using STAR (v2.4.2a) and reads aligning to the transcriptome were quantified using Salmon (v0.6). Differential expression was determined with DESeq2.0 (v1.3) using a model that accounts for sequencing facility as a covariate.

\section{Statistical analysis}

Statistical comparisons of quantitative PCR and immunoblot results were made using Student's t-test.

Significant differences in gene expression were determined using DESeq2.0. Graphs were generated in the R software package and error bars represent the standard error.

\section{Preparation of ${ }^{13} \mathrm{C}$-labeled CS disaccharide calibrants}

Four ${ }^{13} \mathrm{C}$-labeled CS disaccharides were prepared from three ${ }^{13} \mathrm{C}$-labeled CS 8-mers, including ${ }^{13} \mathrm{C}$-labeled CSA 8-mer, ${ }^{13} \mathrm{C}$-labeled CS-C 8-mer and ${ }^{13} \mathrm{C}$-labeled CS-E 8-mer, as described in Supplemental Figure 1A. The synthesis of 8 -mers was completed using the enzymatic approach $(33,34)$. The only exception from previously published procedures is that a ${ }^{13} \mathrm{C}$-labeled UDP-GlcA was used to replace unlabeled UDP-GlcA during the synthesis to introduce the ${ }^{13} \mathrm{C}$-labeled GlcA residue to the 8 -mer products. The synthesis of UDP- $\left[{ }^{13} \mathrm{C}\right] \mathrm{GlcA}$ was completed enzymatically from $\left[{ }^{13} \mathrm{C}\right]$ glucose as described previously ${ }^{(35,36)}$. The structures of 8 -mer products were confirmed by electrospray ionization mass spectrometry.

The 8-mers were then subjected to the digestion of recombinant chondroitin ABCase (Flavobacterium heparinum) to yield the disaccharides. The chondroitin ABCase digestion solution contained 3.55 mL 8-mers (2 
$\mathrm{mg} / \mathrm{mL}$ ), $400 \mu \mathrm{L}$ enzymatic buffer (100 mM sodium acetate/2 mM calcium acetate buffer $(\mathrm{pH} 6.0)$ containing

$0.1 \mathrm{~g} / \mathrm{L} \mathrm{BSA})$, and $50 \mu \mathrm{L}$ of recombinant chondroitin ABCase $(3 \mathrm{mg} / \mathrm{mL})$. The reaction mixture was incubated at $37^{\circ} \mathrm{C}$ overnight. The extent of reaction completion was monitored by the strong anion exchange chromatography on a Pro Pac PA1 column $(9 \times 250 \mathrm{~mm}$, Thermo Fisher Scientific) by measuring the absorbance at $232 \mathrm{~nm}$. The purification of ${ }^{13} \mathrm{C}$-labeled CS disaccharides was performed on the Q-Sepharose fast flow column. Mobile phase A was 20 mM NaOAc, pH 5.0 and mobile phase $\mathrm{B}$ was $20 \mathrm{mM}$ NaOAc and $1 \mathrm{M}$ $\mathrm{NaCl}, \mathrm{pH}$ 5.0. The elution gradient with a flow rate of $1 \mathrm{~mL} / \mathrm{min}$ was used. The absorbance at $232 \mathrm{~nm}$ was scanned and recorded. After purification, the disaccharides were desalted on a Sephadex G-10 column. The quantification of ${ }^{13} \mathrm{C}$-labeled disaccharide calibrants was performed based on the standard curve of commercially available native CS disaccharide standards (Iduron, UK).

\section{Structure analysis of ${ }^{13} \mathrm{C}$-labeled disaccharide calibrants}

A strong anion exchange column Pro Pac PA1 (9×250 mm, Thermo Fisher Scientific) was used to determine the purity of ${ }^{13} \mathrm{C}$-labeled disaccharides after purification. Mobile phase $\mathrm{A}$ was $3 \mathrm{mM} \mathrm{NaH}_{2} \mathrm{PO}_{4}, \mathrm{pH}$ 3.0. Mobile phase $\mathrm{B}$ was $3 \mathrm{mM} \mathrm{NaH}_{2} \mathrm{PO}_{4}$ and $2 \mathrm{M} \mathrm{NaCl}$, $\mathrm{pH}$ 3.0. The gradient was as follows: 0-20 min 0-20\% $\mathrm{B}, 20-65$ $\min 20-95 \%$ B, 65-72 $\min 95 \%$ B and $72-75 \min 95-100 \%$ B with flow rate of $1 \mathrm{~mL} / \mathrm{min}$. The UV absorbance at $232 \mathrm{~nm}$ was scanned and recorded. Each disaccharide calibrant was eluted as doublet peaks from ProPac PA1 column. Such profiles are typical for the CS disaccharides due to the chemistry of the anomeric carbon. Both $\square$-anomer and $\square$-anomer are present in the disaccharides.ESI-MS (Thermo Scientific TSQ Fortis) analysis was used to confirm the molecular weight of each ${ }^{13} \mathrm{C}$-labeled disaccharide. The ESI-MS analysis was performed in the negative ion mode and with the following parameters: Negative ion spray voltage at $3.0 \mathrm{kV}$, sheath gas at $15 \mathrm{Arb}$, ion transfer tube temp at $320^{\circ} \mathrm{C}$ and vaporizer temp at $100^{\circ} \mathrm{C}$. The mass range was set at 200-800. The measured MWs for the ${ }^{13} \mathrm{C}$-labeled CS disaccharide calibrants are: for Di-0S calibrant was 385.2 (Calc MW = 385.1); for Di-4S calibrant was 465.1 (Calc MW = 465.1); for Di-6S calibrant was 465.1 (Calc MW = 465.1); and for Di-4S6S calibrant was 545.2 (Calc MW = 545.0). From our ESI-MS analysis, we did not observe unlabeled CS disaccharides in the calibrants, suggesting that the calibrants had very high isotopic purity that was suited for the quantitative analysis. 


\section{Quantification of the ${ }^{13} \mathrm{C}$-labeled disaccharide calibrants}

The CS native disaccharides (Iduron, UK) were dissolved in water and diluted to the concentration of 5, 10, 20, 40 and $80 \mu \mathrm{g} / \mathrm{mL} .50 \mu \mathrm{L}$ of the diluted CS was injected into HPLC to make the standard curve to quantify the ${ }^{13} \mathrm{C}$-labeled disaccharide calibrants. The stock solutions of four ${ }^{13} \mathrm{C}$-labeled disaccharide calibrants were diluted to 10 or 20 times and then $50 \mu \mathrm{L}$ was injected to the HPLC analysis. The concentration of the ${ }^{13} \mathrm{C}$-labeled disaccharide calibrants stocks were determined by comparing the peak areas at $232 \mathrm{~nm}$ with unlabeled disaccharides.

\section{Linear dynamic range determination}

Individual stock solutions of four CS unlabeled disaccharides (Iduron, UK) were prepared in water at $1 \mathrm{mg} / \mathrm{mL}$. A stock solution of the mixture of the four unlabeled disaccharides, with the final concentration of $0.25 \mathrm{mg} / \mathrm{mL}$ for each disaccharide, was obtained by mixing an equal volume of four individual stock solutions. The linear dynamic range of the working solutions was determined by a serial dilution of the mixture stock solution in water to obtain a range of final concentrations (Supplemental Figure 1B-E). The ${ }^{13} \mathrm{C}$-labeled CS disaccharide were added to the linear dynamic range working solutions as an internal standard mixture stock solution to the final concentration of $40 \square \mathrm{g} / \mathrm{mL}$ of ${ }^{13} \mathrm{C}$-labeled di-4S, di-6S and di-4S6S respectively and $8 \square \mathrm{g} / \mathrm{mL}$ of di-0S. The linear dynamic range working solutions containing ${ }^{13} \mathrm{C}$-labeled internal standard were freeze-dried and reconstituted in the 20- $\mu \mathrm{L}$ mouse plasma. The reconstituted solutions were filtered by passing through a YM3KDa spin column (Millipore) and washed twice with deionized water to recover the disaccharides in the eluent. The AMAC (2-aminoacridone)-derivatization of lyophilized disaccharides was carried out by adding 6 $\mu \mathrm{L}$ of $0.1 \mathrm{M}$ AMAC solution in DMSO/glacial acetic acid $(17: 3, \mathrm{v} / \mathrm{v})$ and incubating at room temperature for 15 min. Then $6 \mu \mathrm{L}$ of $1 \mathrm{M}$ aqueous sodium cyanoborohydride (freshly prepared) was added to this solution, where AMAC represents 2-aminoacridone purchased from Sigma Aldrich. The reaction mixture was incubated at 45

${ }^{\circ} \mathrm{C}$ for $2 \mathrm{~h}$. After incubation, the reaction solution was centrifuged to obtain the supernatant that was subjected to the LC-MS/MS analysis. 


\section{LC-MS/MS analysis}

The analysis of AMAC-labeled disaccharides was performed on a Vanquish Flex UHPLC System (Thermo Fisher Scientific) coupled with TSQ Fortis triple-quadrupole mass spectrometry as the detector. The C18 column (Agilent InfinityLab Poroshell 120 EC-C18 $2.7 \mu \mathrm{m}, 4.6 \times 50 \mathrm{~mm}$ ) was used to separate the AMAClabeled disaccharides. Mobile phase A was $50 \mathrm{mM}$ ammonium acetate in water. Mobile phase B is methanol. The elution gradient of from 5-45\% mobile phase B in $10 \mathrm{~min}$, followed by isocratic $100 \%$ mobile phase B in 4 min and then isocratic $5 \%$ mobile phase $B$ in 6 min was performed at a flow rate of $0.3 \mathrm{ml} / \mathrm{min}$. On-line triplequadrupole mass spectrometry operating in the multiple reaction-monitoring (MRM) mode was used as the detector. The ESI-MS analysis was operated in the negative-ion mode using the following parameters: Neg ion spray voltage at $4.0 \mathrm{kV}$, sheath gas at $45 \mathrm{Arb}$, aux gas $15 \mathrm{arb}$, ion transfer tube temp at $320^{\circ} \mathrm{C}$ and vaporizer temp at $350{ }^{\circ} \mathrm{C}$. TraceFinder software was applied for data processing. The normalized peak areas of the ${ }^{13} \mathrm{C}-$ labeled calibrants were plotted against the concentrations of linear dynamic working solutions.

\section{Analysis of CS and HS from tissues}

CS was extracted from 5 NML and 11 FLC tissues. All tissues were excised, homogenized, and defatted by suspension and vortex in chloroform/methanol mixtures $(2: 1,1: 1,1: 2(\mathrm{v} / \mathrm{v}))$. The defatted tissues were dried and weighed to obtain the dry weight. The dried and defatted tissues were digested with Pronase $\mathrm{E}$ (10 mg:1 g (w/w), tissue/Pronase $\mathrm{E}$ ) at $55^{\circ} \mathrm{C}$ for $24 \mathrm{~h}$ to degrade the proteins. CS was recovered from the digested solution using a DEAE-column. DEAE column mobile phase A was $20 \mathrm{mM}$ Tris, pH 7.5 and $50 \mathrm{mM} \mathrm{NaCl}$, and mobile phase B was $20 \mathrm{mM}$ Tris, $\mathrm{pH} 7.5$ and $1 \mathrm{M} \mathrm{NaCl}$. After loading the digested solution, the column was washed with 10-column volumes of buffer A to discard the contaminants, following by 10 column-volumes of buffer $B$ to elute the CS fraction. The CS eluting from the DEAE column was desalted using an YM-3KDa spin column and washed three times with deionized water to remove salt. A known amount ${ }^{13} \mathrm{C}$-labeled calibrants were added to the digestion solution. The $200 \mu \mathrm{L}$ of enzymatic buffer ( $100 \mathrm{mM}$ sodium acetate/2 mM calcium acetate buffer ( $\mathrm{pH} 7.0$ ) containing $0.1 \mathrm{~g} / \mathrm{L} \mathrm{BSA})$, and the $60 \mu \mathrm{L}$ of chondroitin ABCase $(3 \mathrm{mg} / \mathrm{ml})$ was added to digest the retentate on the filter unit of the YM-3KDa column. The column was incubated at $37^{\circ} \mathrm{C}$ overnight. The CS disaccharides and calibrants were recovered by centrifugation, and the filter unit was washed twice 
with $200 \mu \mathrm{L}$ of deionized water. The collected filtrates were freeze-dried before the AMAC derivatization. The AMAC label and LC-MS/MS analysis of the collected disaccharides of tissues was performed as described above. The amount of tissue CS was determined by comparing the peak area of native disaccharide to each calibrant.

HS was extract from 2 NML tissues and 4 FLC tissues respectively. The method for the analysis of HS followed the procedures described in a previous publication ${ }^{(37)}$.

Three CS disaccharides, including Ddi-2S, Ddi-2S6S and Ddi-2S4S, were only performed relative quantitation as the ${ }^{13} \mathrm{C}$-labeled disaccharides were unavailable. Standard curves of these three disaccharides were generated using unlabeled disaccharide standards that were purchased from Iduron.

\section{Data availability}

Previously published RNA-seq data can be downloaded from Gene Expression Omnibus (GEO) using the following GEO accession number: GSE181922. Previously published RNA-seq and ChRO-seq can be downloaded from the European Genome-Phenome Archive (EGA) using the following EGA accession number: EGAS00001004169.

\section{$\underline{\text { Results }}$}

Chondroitin but not heparan sulfate biosynthesis genes are increased in fibrolamellar carcinoma

Tissue samples from patients with FLC were acquired at the time of surgical procedures through a collaboration with the Fibrolamellar Cancer Foundation (FCF) and subjected to RNA extraction and messenger RNA sequencing ( $n=23$ tumor samples and $n=4$ adjacent non-malignant liver (NML) samples), as previously reported ${ }^{(5)}$. We then performed an analysis of differential gene expression for enzymes related to glycosaminoglycan (GAG) biosynthesis, focusing on hyaluronic acid (HA), heparan sulfate (HS), and chondroitin sulfate (CS). 
The expression of hyaluronic acid synthase 1-3 in FLC did not meet our standard threshold of robust expression (>500 normalized counts), and therefore the HA pathway was not considered for further analysis. We then assessed the expression of genes which catalyze the formation of the common tetrasaccharide linker required for HS and CS proteoglycan production (Figure 1A). The initial addition of xylose to serine residues in polypeptide chains is catalyzed by xylosyltransferases ( $X Y L T 1$ or $X Y L T 2){ }^{(38)}$. This reaction is followed first by the addition of two galactose molecules (catalyzed by $\beta 1,4$-galactosyltransferase-I (B4GALT7) and $\beta 1,3$ galactosyltransferase-I (B3GALT6)), and subsequently by the addition of glucuronic acid (catalyzed by $\beta 1,3-$ glucuronyltransferase- I $(B 3 G A L T 3))^{(39,40)}$. We found that the expression in FLC of the genes that code for these enzymes meets the threshold criteria but is not significantly different relative to NML.

We next interrogated those genes encoding enzymes responsible for HS and CS polymerization. HS chain formation begins with the addition of $\mathrm{N}$-acetylglucosamine (GlcNAc) to the common linker by $N$ acetylglucosaminyltransferase (EXTL2), followed by the addition of glucuronic acid (GlcA) by exostosin glycosyltransferases (EXT1 and EXT2) to create the HS disaccharide ${ }^{(20)}$ (Figure 1A). We found that the expression of EXTL2 and EXT2 is unchanged in FLC, and that EXT1 is significantly decreased (Figure 1B). Additionally, HS chains undergo deacetylation and sulfation, catalyzed by the enzyme N-deacetylase and Nsulfotransferase 1 (NDST1) ${ }^{(41)}$, as a critical maturation step and there is no significant change in the expression of this gene in FLC (Figure 1B).

$\mathrm{CS}$ chain elongation begins with the addition of $\mathrm{N}$-acetylgalactosamine (GalNAc) to the common linker by CS GalNAc transferase 1 or 2 (CSGALNACT1 and CSGALNACT2), followed by the addition of GICA by an enzyme complex containing chondroitin synthase 1 (CHSY1) and chondroitin polymerizing factor (CHPF) to create the CS disaccharide ${ }^{(42)}$ (Figure 1A). We found that the expression of CSGALNACT1 is significantly increased (8-fold, adjusted $\mathrm{P}=7.6 \times 10^{-9}$ ) in FLC compared to NML (Figure 1C). The expression levels of CSGALNACT2, CHPF, and CHSY1 are unchanged in FLC; however, CHPF is more abundant in FLC than any of the HS polymerizing factors (Figure 1C).

Given that HS and CS chains share a common linker, the stoichiometric ratio of EXTL2 and CSGALNACT enzymes is the primary factor determining whether HS or CS chains will be generated ${ }^{(43)}$. We compared the expression of CSGALNACT1 to EXTL2 within each of the FLC and NML samples and found that 
CSGALNACT1 is on average 4.5 times $(\mathrm{P}=0.017)$ more abundant than EXTL2 (Figure 1D) in FLC samples, while being roughly equal in NML samples ( 0.77 fold). In an independent cohort of patients (FLC $n=11$ and NML $n=4)$ we confirmed by real-time quantitative PCR (RT-qPCR) that CSGALNACT1 expression is increased $>10$-fold (Figure 1E). A similar result was obtained when the analysis was restricted only to matched patient samples (Figure 1F).

\section{Chondroitin sulfate chains are aberrantly elevated in fibrolamellar carcinoma}

The gene expression analysis is strongly suggestive of increased CS, but not HS, abundance in FLC. To test this hypothesis, we quantified HS and CS abundance in FLC using a novel chemical analytical method. Due to the relatively low abundance of CS from biological tissues, a new quantitative CS analytical method with high sensitivity was developed for this study. Disaccharide analysis is a commonly used approach to analyze the structure of CS polysaccharides. The method involves the degradation of CS polysaccharides into disaccharides using chondroitin ABCase, and the resultant disaccharides were subjected to liquid chromatography coupled with tandem mass spectrometry (LC-MS/MS) analysis (Figure 2A). Furthermore, summing up the amounts of individual disaccharides from the digested CS provides the total amount of CS. To increase the quantitation capability, we employed four ${ }^{13} \mathrm{C}$-labeled CS disaccharide calibrants as internal standards, including di-0S, di-4S, di-6S and di-4S6S (Supplemental Figure S1). The ${ }^{13} \mathrm{C}-$ labeled CS disaccharide calibrants were obtained from three uniquely designed ${ }^{13} \mathrm{C}$-labeled CS octasaccharides (8-mers) that were synthesized by an enzymatic approach. The di-4S disaccharide is found in CS-A polysaccharide, whereas di-6S and di-4S6S are found in CS-C and CS-E polysaccharides, respectively. The di-0S disaccharide is found in all subtype CS polysaccharides from biological sources. The inclusion of ${ }^{13} \mathrm{C}$-labeled calibrants eliminated batch-to-batch variations, increasing the data consistency (Supplemental Figure 1B-E).

Using this highly sensitive method, we discovered that total CS in FLC tumor tissue compared with nonmalignant liver ( $F L C=11, N M L=5)$ was significantly increased (5.9-fold, $\mathrm{P}=0.033$ ) (Figure 2B) and the amount of non-sulfated CS (di-0S) is also similarly increased (6.7-fold, $\mathrm{P}=0.035)$ in FLC (Figure 2C). However, there was no difference in total HS in a subset of FLC tumors ( $F L C=4, N M L=2)$ (Figure 2D). 
The sulfation of CS chains is mediated by a family of chondroitin sulfotransferase (CHST) enzymes that have specificity for particular positions of oxygen on the CS disaccharide. We interrogated the expression of key CHST genes in FLC and measured the abundance of sulfated CS. Monosulfation of the 4-OH position of the GalNAc residue (CS di-4S) (Figure 3A) is catalyzed by chondroitin 4-O sulfotransferase (CHST11), and we found that the expression of this gene is significantly increased in FLC (2.6-fold, adjusted P=0.03) (Figure 3B). Correspondingly, we also found that CS di-4S is highly elevated in FLC (5.7-fold, $\mathrm{P}=0.043)$ (Figure 3C). A second common site for monosulfation is at the $6-\mathrm{OH}$ position of the GalNAc residue (CS di-6S) (Figure 3D), which is catalyzed by chondroitin 6-O sulfotransferase (CHST3). We found that although the expression of CHST3 in FLC is lower than that of CHST11, its levels are also significantly increased compared to NML (2.3fold, adjusted $\mathrm{P}=0.02$ (Figure 3E). Likewise, although CS di-6S is not as abundant as CS di-4S, it is similarly increased in FLC (9-fold, $\mathrm{P}=0.023)$ (Figure 3F).

CS chains with the disaccharide repeat of di-4S can serve as a substrate for GalNAc 4-sulfate 6-Osulfotransferase (CHST15) or uronyl 2-O-sulfotransferase (UST), respectively, resulting in CS di-4S6S and CS di-2S4S (Figure 3G, 3J). We found that the expression of CHST15 is modestly, but not significantly, increased (Figure 3H) and that the expression of UST is unchanged (Figure 3K) in FLC. Consistent with these findings, we found that the abundance of CS di-4S6S is modestly, but not significantly, increased (Figure 3I), and the abundance of CS di-2S4S is unchanged (Figure 3L). We performed a similar quantification for HS and found that none of the sulfated subtypes are significantly altered in FLC (Supplemental Figure 2A-G), consistent with the finding that total HS abundance is unchanged in FLC (Figure 1D). In an independent patient cohort we found by RT-qPCR analysis that the expression of CHST11 is significantly increased in FLC in all samples (Supplemental Figure 3A) as well as in matched samples only (Supplemental Figure 3B) and that CHST3 is trending upward in FLC (Supplemental Figure 3C and D). Taken together, these molecular and chemical findings strongly indicate that FLC tumors are marked by aberrant levels of total CS as well as specific sulfated subtypes.

Versican is the primary chondroitin sulfate-associated protein in fibrolamellar carcinoma 
We next assessed changes in the expression of CS associated proteins (CSAPS) in FLC. We identified three CSAPs significantly up-regulated in FLC compared to NML: chondroitin sulfate proteoglycan 8 (CSPG8, also known as CD44), chondroitin sulfate proteoglycan 4 (CSPG4), and versican (VCAN). Notably, the foldchange and abundance of VCAN in FLC is substantially greater than the other two ( VCAN 10-fold, $\mathrm{P}=8.5 \times 10^{-}$ 6; CD44 2-fold, P=0.11; CSPG4 4.5-fold, $\mathrm{P}=0.0016$ ) (Figure 4A). We measured VCAN by RT-qPCR in an independent FLC patient cohort and observed a significant increase in FLC in all samples (18.5-fold, $\mathrm{P}=0.0095)$ (Figure 4B) as well as in matched samples only (15.5-fold, $\mathrm{P}=0.04)$ (Figure 4C). Western blot analysis of three matched FLC/NML pairs confirmed dramatic elevation of VCAN protein in FLC (average 200-fold) (Figure 4D, E). Specifically, VCAN protein is variable but abundant in the tumor tissue from all three FLC patients, while virtually absent in the adjacent non-malignant samples (Figure 4D, lower panel). Finally, we performed immuno-histofluorescent (IHF) staining on two matched FLC/NML pairs of samples and confirmed that VCAN protein is robustly, though non-uniformly, detected only in tumor tissue (Figure 4F).

Chondroitin sulfate GalNAc transferase 1 and versican are more altered in FLC than in most other cancer types and correlate with DNAJB1-PRKACA levels

Next, we sought to compare the expression of CSGALNACT1 and VCAN in FLC to other cancer types. Specifically, we queried The Cancer Genome Atlas (TCGA) database, which houses RNA-seq data from 25 other cancer types. We found that the change in expression of CSGALNACT1 in FLC (relative to corresponding non-malignant tissue) is second only to cholangiocarcinoma (Figure 5A). Strikingly, the change in expression of $V C A N$ is greatest in FLC, followed by cholangiocarcinoma (Figure 5B). Further analysis revealed that VCAN and CSGALNACT1 are correlated by RNA-seq (Figure 5C) as well as by RT-qPCR in an independent cohort (Figure 5D). Additionally, we found by RT-qPCR that the expression of DP correlates with both VCAN (Figure 5E) and CSGALNACT1 (Figure 5F).

Versican is expressed in FLC transformed epithelial and tumor-associated, activated stellate cells in fibrolamellar carcinoma 
To identify which cells are likely responsible for VCAN production and secretion we performed singlecell assay for transposase-accessible chromatin followed by sequencing (scATAC-seq) on NML, primary FLC tumor, and metastatic FLC tumor samples $(n=3)$. We used a previously described nuclei isolation protocol (44) and obtained data on nearly 9,500 nuclei total. After data analysis with ArchR ${ }^{(45)}$ (Methods), non-linear dimensionality reduction via UMAP revealed eight different clusters (Figure 6A). By analyzing open chromatin signal at established markers of human liver cell types ${ }^{(46)}$, we assigned each cluster to a specific cell type (Figure 6A, Supplemental Figure 4A-D). We also analyzed open chromatin in the deleted region of chromosome 19 to identify the cells that likely harbor the deletion and therefore the DP fusion (Supplemental Figure 5A, B). We then queried for ATAC signal associated with CSGALNACT1 and detected robust enrichment in the FLC primary and metastatic tumor transformed epithelial cell clusters (Figure 6B). As expected, there is little to no signal for open chromatin at CSGALNACT1 in any non-malignant cell types (Figure 6B, C). A similar analysis for VCAN revealed the strongest signal in tumor-associated activated stellate cells and second-most in tumor transformed epithelial cells (Figure 6D, E). These findings suggest that while CS synthesis (via CSGALNACT1) is likely exclusively taking place in tumor transformed epithelial cells, the primary CS associated protein in FLC, VCAN, is produced and secreted from both activated stellate cells as well as tumor transformed epithelial cells (Figure 7).

\section{Discussion}

FLC is an aggressive liver cancer that lacks an effective chemotherapeutic remedy. There are several factors contributing to low survival rates in FLC, including vague manifestations, lack of comorbidities, and resistance to general therapeutics. FLC is genetically characterized by the DNAJB1-PRKACA (DP) fusion, but efforts to identify specific inhibitors of DP, without targeting wild-type PRKACA, have been unsuccessful. Additionally, while it is known that DP is sufficient for tumor initiation, it is unclear whether DP expression is essential for tumor maintenance, progression, and metastasis. It has been established in the study of other cancer types that the pericellular environment, including proteoglycans, plays an important role in defining 
tumor behavior ${ }^{(12,15)}$. However, to date, no study has investigated GAGs and proteoglycans in FLC. In this study, we sought to bridge this knowledge gap.

The three major classes of GAGs are hyaluronic acid (HA), heparan sulfate (HS), and chondroitin sulfate (CS). Of these, only HA is found as a free polymer generated by hyaluronic acid synthetase 1-3 (HAS13). The expression levels of these enzymes were found to be extremely low in FLC and, therefore, they were not considered further. HS and CS chains are conjugated to proteins by a shared tetrasaccharide linker. The enzymes responsible for the synthesis of this linker exhibit robust expression in FLC but are unchanged relative to non-malignant liver (NML) tissue. The decision by cells to generate HS or CS sidechains is dependent on stoichiometric competition between the enzymes $N$-acetylglucosaminyltransferase (EXTL2), responsible for HS chains, and chondroitin GaINAc transferase (CSGALNACT1), responsible for CS chains. We found that the ratio of CSGALNACT1 to EXTL2 levels is dramatically elevated in FLC, pointing to CS chains as the key component of the extracellular matrix in FLC.

A major innovation and strength of this study is the development and implementation of a highly sensitive method for quantifying HS and CS disaccharides in patient tissues. This novel assay confirmed that the alterations in expression of CS biosynthetic genes observed in FLC lead to dramatic changes in CS abundance. The quantity of CS in FLC tissue relative to NML was greater than 5.9-fold and the relative difference between CS and HS in tumor tissue was 4.3-fold. Additionally, this assay independently quantifies sulfated forms of CS and HS disaccharides. As HS abundance is unchanged in FLC tissue, it is not surprising that there are no significant differences in the seven sulfated forms of HS that we measured. The analysis of sulfated forms of CS showed that nonsulfated CS and two forms of monosulfated CS (CS di-4S and CS di-6S) are significantly increased in FLC tissue. The increased abundance of CS di-4S and CS di-6S is concordant with gene expression increases in associated chondroitin sulfotransferases (CHST11/3), again showing that changes in gene expression accurately correspond with changes in chemical abundance. It has been observed in hepatocellular carcinoma (HCC) that increased expression of $C H S T 11 / 13$, which are functionally equivalent, are upregulated in metastatic samples ${ }^{(47)}$, which may promote sustained Wnt signaling ${ }^{(48)}$. One limitation of the quantitative analysis for the CS chains with di-2S4S should be noted. We were unable to synthesize ${ }^{13} \mathrm{C}$ - 
labeled di2S4S; therefore, the quantitation was completed using the relative quantitation method. However, this should not affect our conclusions, as the levels of di-2S4S are the same in FLC compared to NML tissues.

Given the abundant increase of CS in FLC tissue, and the high expression of the CS-associated protein VCAN, we conjectured that the levels of CSGALNACT1 and VCAN would be correlated. Indeed, we found that there is a positive correlation between the two genes, and between either gene and DP. Consistent with this finding, in a previous report we had demonstrated that the expression of DP in an FLC cell model increases VCAN expression ${ }^{(5)}$. We found in this study that the levels of VCAN are upregulated in FLC more than in any other cancer type for which expression data is publicly available through TCGA. Cholangiocarcinoma (CCA) is the closest to FLC in terms of CSGALNACT1 and VCAN upregulation. Intriguingly, chondroitin polymerizing factor (CHPF) has been reported recently to promote CCA cell growth and invasive potential ${ }^{(49)}$. Additionally, chondroitin synthase 1 (CHSY1) has been reported to suppress apoptosis in colorectal cancer (50) and promote migration in hepatocellular carcinoma (HCC) ${ }^{(51)}$.

Another major component of this study is the first-ever single-cell ATAC-seq analysis of FLC. All prior genome-scale analyses of FLC have been performed on bulk tumors and the only published single-cell analysis related to this cancer involves a patient-derived xenograft (PDX), not a primary tumor ${ }^{(52)}$. Our study overcomes these limitations and provides the first glimpse into FLC tumor tissue complexity. We focused on resolving gene locus activity at single-cell resolution and identified chromatin accessibility at the CSGALNACT1 and VCAN loci in the primary population of FLC cells. Transformed epithelial cells were identified as the primary source of CSGLANACT1 locus activity, whereas proliferating stellate cells were found to be the cell type with the strongest VCAN signal. This finding suggests that communication between transformed DP+ liver epithelial cells and stellate cells may be critical to FLC disease progression.

The expression and secretion of VCAN from activated stellate cells is a normal response to liver injury (53-56). The data generated in this study suggest that FLC cells upregulate CSGALNACT1 and VCAN in a DPdependent manner and begin secreting CS-VCAN proteoglycan into the extracellular matrix. The increased accumulation of VCAN may sequester higher concentrations of growth factors, or increase mechanical tension, and induce the activation of quiescent stellate cells. Upon activation, these stellate cells proliferate and secrete VCAN as a normal response to a perceived injury. However, the rapid accumulation of VCAN may promote 
proliferation and migration of FLC cells, creating a feed-forward loop, directly though CS signaling, mechanotransduction, and/or growth factor presentation.

The role for stellate cells to promote fibrosis and predispose the liver to cancer formation is well established ${ }^{(57)}$ and multiple HS proteoglycans have been implicated in this role, including syndecans ${ }^{(58-61)}$, glypicans ${ }^{(62-64)}$, and even free HS disaccharides ${ }^{(65)}$. Additionally, CS proteoglycans, including VCAN and CD44, have been implicated in both hepatic fibrosis and HCC formation ${ }^{(31,66,67)}$. However, these findings suggest that stellate-mediated fibrosis precedes and contributes to cancer formation. Given that FLC patients lack underlying fibrotic conditions, such as cirrhosis, the relationship in FLC may be fundamentally different. Further investigation in the transcriptional activation of VCAN in FLC and the identification of VCAN associated growth factors is warranted.

We have implemented several novel methods to provide the first high-resolution analysis of proteoglycan biology in FLC tumors. Our findings motivate further investigation of VCAN in FLC progression. Future research may also study the effects of VCAN inhibitors on FLC cell drug resistance, growth and/or metastasis.

\section{Acknowledgments}

We are very grateful for funding from the Fibrolamellar Cancer Foundation (awarded to P.S.), which permitted the execution of this project. We acknowledge the service provided by the Cornell Genomics Facility for sequencing. We are especially indebted to the Cornell Genomics Innovation hub, including Jen Grenier, Adrian McNairn, and Paul Munn, for their invaluable insight and input for single-cell ATAC library preparation. Finally, we also thank Larry Bonassar, Jongkil Kim, and Cora Demler for valuable discussions during the study. Chemical structures were created with Chemdraw (by PerkinElmer). Schematics were created with BioRender.com.

\section{Author contributions}

Conceptualization, A.B.F., Jian.L., P.S.; Methodology, Jine.L., Jian.L., B.S.; Software, A.R.F., M.K.; Formal Analysis, A.B.F., Jine.L., A.R.F., M.K.; Investigation, A.B.F., Jine.L., A.R.F.; Data Curation, A.R.F., M.K.; 
Writing - Original Draft, A.B.F., Jian.L., P.S.; Writing - Reviewing \& Editing, Jine.L., A.R.F., M.K., P.D.S, Z.W., L.M.R.; Visualization, A.B.F., Jine.L., A.R.F., M.K.; Funding Acquisition, P.S.; Resources, P.D.S, Z.W.; Supervision, Jian.L., P.S.

\section{$\underline{\text { Inclusion and Diversity }}$}

We worked to ensure gender balance in the recruitment of human subjects. We worked to ensure ethnic or other types of diversity in the recruitment of human subjects. One or more of the authors of this paper selfidentifies as an underrepresented ethnic minority in science. While citing references scientifically relevant for this work, we also actively worked to promote gender balance in our reference list. The author list of this paper includes contributors from the location where the research was conducted who participated in the data collection, design, analysis, and/or interpretation of the work.

\section{References}

1. Eggert T, McGlynn KA, Duffy A, Manns MP, Greten TF, Altekruse SF. Epidemiology of fibrolamellar hepatocellular carcinoma in the USA, 2000-10. Gut. 2013;62(11):1667-8.

2. Ramai D, Ofosu A, Lai JK, Gao ZH, Adler DG. Fibrolamellar Hepatocellular Carcinoma: A Population-Based Observational Study. Dig Dis Sci. 2021;66(1):308-14.

3. Honeyman JN, Simon EP, Robine N, Chiaroni-Clarke R, Darcy DG, Lim, II, et al. Detection of a recurrent DNAJB1PRKACA chimeric transcript in fibrolamellar hepatocellular carcinoma. Science. 2014;343(6174):1010-4.

4. Graham RP, Jin L, Knutson DL, Kloft-Nelson SM, Greipp PT, Waldburger N, et al. DNAJB1-PRKACA is specific for fibrolamellar carcinoma. Mod Pathol. 2015;28(6):822-9.

5. Dinh TA, Sritharan R, Smith FD, Francisco AB, Ma RK, Bunaciu RP, et al. Hotspots of Aberrant Enhancer Activity in Fibrolamellar Carcinoma Reveal Candidate Oncogenic Pathways and Therapeutic Vulnerabilities. Cell Rep. 2020;31(2):107509.

6. Dinh TA, Vitucci EC, Wauthier E, Graham RP, Pitman WA, Oikawa T, et al. Comprehensive analysis of The Cancer Genome Atlas reveals a unique gene and non-coding RNA signature of fibrolamellar carcinoma. Sci Rep. 2017;7:44653.

7. Simon EP, Freije CA, Farber BA, Lalazar G, Darcy DG, Honeyman JN, et al. Transcriptomic characterization of fibrolamellar hepatocellular carcinoma. Proc Natl Acad Sci U S A. 2015;112(44):E5916-25.

8. Dinh TA, Jewell ML, Kanke M, Francisco A, Sritharan R, Turnham RE, et al. MicroRNA-375 Suppresses the Growth and Invasion of Fibrolamellar Carcinoma. Cell Mol Gastroenterol Hepatol. 2019;7(4):803-17.

9. Farber BA, Requena, D., Bhanot, U.K., Lalazar, G., Simon, E.P., Hammond, W.J., La Quaglia, M.P. and Simon, S.M. Non coding RNA analysis in fibrolamellar hepatocellular carcinoma. Oncotarget. 2018;9(12):10211-27.

10. Lalazar G, Requena D, Ramos-Espiritu L, Ng D, Bhola PD, de Jong YP, et al. Identification of Novel Therapeutic Targets for Fibrolamellar Carcinoma Using Patient Derived Xenografts and Direct from Patient Screening. Cancer Discov. 2021.

11. Graham RP, Torbenson MS. Fibrolamellar carcinoma: A histologically unique tumor with unique molecular findings. Semin Diagn Pathol. 2017;34(2):146-52.

12. Pickup MW, Mouw JK, Weaver VM. The extracellular matrix modulates the hallmarks of cancer. EMBO Rep. 2014;15(12):1243-53. 
13. Vitale D, Kumar Katakam S, Greve B, Jang B, Oh ES, Alaniz L, et al. Proteoglycans and glycosaminoglycans as regulators of cancer stem cell function and therapeutic resistance. FEBS J. 2019;286(15):2870-82.

14. Walker C, Mojares E, Del Rio Hernandez A. Role of Extracellular Matrix in Development and Cancer Progression. Int J Mol Sci. 2018;19(10).

15. Brassart-Pasco S, Brezillon S, Brassart B, Ramont L, Oudart JB, Monboisse JC. Tumor Microenvironment:

Extracellular Matrix Alterations Influence Tumor Progression. Front Oncol. 2020;10:397.

16. Elgundi Z, Papanicolaou M, Major G, Cox TR, Melrose J, Whitelock JM, et al. Cancer Metastasis: The Role of the Extracellular Matrix and the Heparan Sulfate Proteoglycan Perlecan. Front Oncol. 2019;9:1482.

17. Iozzo RV, Sanderson RD. Proteoglycans in cancer biology, tumour microenvironment and angiogenesis. J Cell Mol Med. 2011;15(5):1013-31.

18. Nallanthighal S, Heiserman JP, Cheon DJ. The Role of the Extracellular Matrix in Cancer Stemness. Front Cell Dev Biol. 2019;7:86.

19. Pomin VH, Mulloy B. Glycosaminoglycans and Proteoglycans. Pharmaceuticals (Basel). 2018;11(1).

20. Li JP, Kusche-Gullberg M. Heparan Sulfate: Biosynthesis, Structure, and Function. Int Rev Cell Mol Biol. 2016;325:215-73.

21. Mikami T, Kitagawa H. Biosynthesis and function of chondroitin sulfate. Biochim Biophys Acta. 2013;1830(10):4719-33.

22. Sathyan S, Koshy LV, Balan S, Easwer HV, Premkumar S, Nair S, et al. Association of Versican (VCAN) gene polymorphisms rs251124 and rs2287926 (G428D), with intracranial aneurysm. Meta Gene. 2014;2:651-60.

23. Kloeckener-Gruissem B, Neidhardt J, Magyar I, Plauchu H, Zech JC, Morle L, et al. Novel VCAN mutations and evidence for unbalanced alternative splicing in the pathogenesis of Wagner syndrome. Eur J Hum Genet.

2013;21(3):352-6.

24. Stopschinski BE, Holmes BB, Miller GM, Manon VA, Vaquer-Alicea J, Prueitt WL, et al. Specific glycosaminoglycan chain length and sulfation patterns are required for cell uptake of tau versus alpha-synuclein and beta-amyloid aggregates. J Biol Chem. 2018;293(27):10826-40.

25. Isabelle R. Cohen ADMd, Michael K Naso, Dario Marchetti, David Berd, and Renato V. lozzo. Abnormal Expression of Perlecan Proteoglycan in Metastatic Melanomas. Cancer Research. 1994;54:5771-577.

26. Jiang X, Multhaupt H, Chan E, Schaefer L, Schaefer RM, Couchman JR. Essential contribution of tumor-derived perlecan to epidermal tumor growth and angiogenesis. J Histochem Cytochem. 2004;52(12):1575-90.

27. V.I. GUELSTEIN TAT, V.D. ERMILOVA and A.V. LUUBIMO. MYOEPITHELIAL AND BASEMENT MEMBRANE ANTIGENS IN BENIGN AND MALIGNANT HUMAN BREAST TUMORS. International Journal of Cancer. 1993;53:269-77

28. Kalscheuer S, Khanna V, Kim H, Li S, Sachdev D, DeCarlo A, et al. Discovery of HSPG2 (Perlecan) as a Therapeutic Target in Triple Negative Breast Cancer. Sci Rep. 2019;9(1):12492.

29. Kazanskaya GM, Tsidulko AY, Volkov AM, Kiselev RS, Suhovskih AV, Kobozev VV, et al. Heparan sulfate accumulation and perlecan/HSPG2 up-regulation in tumour tissue predict low relapse-free survival for patients with glioblastoma. Histochem Cell Biol. 2018;149(3):235-44.

30. Sharma B, Handler M, Eichstetter I, Whitelock JM, Nugent MA, lozzo RV. Antisense targeting of perlecan blocks tumor growth and angiogenesis in vivo. J Clin Invest. 1998;102(8):1599-608.

31. Zhangyuan G, Wang F, Zhang H, Jiang R, Tao X, Yu D, et al. VersicanV1 promotes proliferation and metastasis of hepatocellular carcinoma through the activation of EGFR-PI3K-AKT pathway. Oncogene. 2020;39(6):1213-30.

32. Tanaka Y, Tateishi R, Koike K. Proteoglycans Are Attractive Biomarkers and Therapeutic Targets in Hepatocellular Carcinoma. Int J Mol Sci. 2018;19(10).

33. Li J, Sparkenbaugh E, Su G, Zhang F, Xu Y, Xia K, et al. Enzymatic synthesis of chondroitin sulfate E to attenuate bacteria lipopolysaccharide-induced organ failure. ACS Central Sci. 2020;6:1199-207.

34. Li J, Su W, Liu J. Enzymatic synthesis of homogeneous chondroitin sulfate oligosaccharides. Angew Chem Int Ed. 2017;56:11784-7.

35. Zhang X, Han X, Xia K, Xu Y, Yang Y, Oshima K, et al. Circulating heparin oligosaccharides rapidly target the hippocampus in sepsis, potentially impacting cognitive functions. Proc Nati Acad Sci USA. 2019;116:9208-13.

36. Xu Y, Chandarajoti K, Zhang X, Pagadala V, Dou W, Hoppensteadt DM, et al. Synthetic oligosaccharides can replace animal-sourced low-molecular weight heparins. Sci Transl Med. 2017;9:eaan5954. 
37. Wang Z, Arnold K, Xu Y, Pagadala V, Su G, Myatt H, et al. Developing a quantitative method to analyze heparan sulfate using isotopically labeled calibrants. Commun Biol. 2020(3):425.

38. Gotting C, Kuhn J, Kleesiek K. Human xylosyltransferases in health and disease. Cell Mol Life Sci. 2007;64(12):1498-517.

39. Pradman K. Qasba BR, and Elizabeth Boeggeman. Structure and Function of $\beta-1,4-$ Galactosyltransferase. Current Drug Targets. 2008;9(4):292-309.

40. Shimoda Y, Tajima Y, Nagase T, Harii K, Osumi N, Sanai Y. Cloning and expression of a novel galactoside beta1, 3glucuronyltransferase involved in the biosynthesis of HNK-1 epitope. J Biol Chem. 1999;274(24):17115-22.

41. Sheng J, Liu R, Xu Y, Liu J. The dominating role of $\mathrm{N}$-deacetylase/N-sulfotransferase 1 in forming domain structures in heparan sulfate. J Biol Chem. 2011;286(22):19768-76.

42. Izumikawa T, Koike T, Shiozawa S, Sugahara K, Tamura J, Kitagawa H. Identification of chondroitin sulfate glucuronyltransferase as chondroitin synthase-3 involved in chondroitin polymerization: chondroitin polymerization is achieved by multiple enzyme complexes consisting of chondroitin synthase family members. J Biol Chem. 2008;283(17):11396-406.

43. Igarashi M, Takeuchi K, Sugiyama S. Roles of CSGaINAcT1, a key enzyme in regulation of CS synthesis, in neuronal regeneration and plasticity. Neurochem Int. 2018;119:77-83.

44. Darren A. Cusanovich RD, Andrew Adey, Hannah A. Pliner, Lena Christiansen, Kevin L. Gunderson, Frank J. Steemers, Cole Trapnell, Jay Shendure. Multiplex single-cell profiling of chromatin accessibility by combinatorial cellular indexing. Science. 2015;348(6237):910-4.

45. Granja JM, Corces MR, Pierce SE, Bagdatli ST, Choudhry H, Chang HY, et al. ArchR is a scalable software package for integrative single-cell chromatin accessibility analysis. Nat Genet. 2021;53(3):403-11.

46. MacParland SA, Liu JC, Ma XZ, Innes BT, Bartczak AM, Gage BK, et al. Single cell RNA sequencing of human liver reveals distinct intrahepatic macrophage populations. Nat Commun. 2018;9(1):4383.

47. Zhou H, Li Y, Song X, Zhao Y, Cheng L, Zhao L, et al. CHST11/13 Regulate the Metastasis and Chemosensitivity of Human Hepatocellular Carcinoma Cells Via Mitogen-Activated Protein Kinase Pathway. Dig Dis Sci. 2016;61(7):1972-85.

48. Nadanaka S, Kinouchi H, Taniguchi-Morita K, Tamura J, Kitagawa H. Down-regulation of chondroitin 4-Osulfotransferase-1 by Wnt signaling triggers diffusion of Wnt-3a. J Biol Chem. 2011;286(6):4199-208.

49. Duan X YJ, Jiang B, Duan W, Wei R, Zhang H, Mao X. Identification of chondroitin polymerizing factor (CHPF) as tumor promotor in cholangiocarcinoma through regulating cell proliferation, cell apoptosis and cell migration. Cell Cycle. 2021;20(5-6):591-602.

50. Zeng L, Qian J, Luo X, Zhou A, Zhang Z, Fang Q. CHSY1 promoted proliferation and suppressed apoptosis in colorectal cancer through regulation of the NFkappaB and/or caspase-3/7 signaling pathway. Oncol Lett. 2018;16(5):6140-6.

51. Liu CH, Lan CT, Chou JF, Tseng TJ, Liao WC. CHSY1 promotes aggressive phenotypes of hepatocellular carcinoma cells via activation of the hedgehog signaling pathway. Cancer Lett. 2017;403:280-8.

52. Jewell ML, Gibson JR, Guy CD, Hyun J, Du K, Oh SH, et al. Single-Cell RNA Sequencing Identifies Yes-Associated Protein 1-Dependent Hepatic Mesothelial Progenitors in Fibrolamellar Carcinoma. Am J Pathol. 2020;190(1):93-107.

53. Yin C, Evason KJ, Asahina K, Stainier DY. Hepatic stellate cells in liver development, regeneration, and cancer. J Clin Invest. 2013;123(5):1902-10.

54. Friedman SL. Hepatic stellate cells: protean, multifunctional, and enigmatic cells of the liver. Physiol Rev. 2008;88(1):125-72.

55. Sherman MH. Stellate Cells in Tissue Repair, Inflammation, and Cancer. Annu Rev Cell Dev Biol. 2018;34:333-55. 56. Sanz-García C, Fernández-Iglesias A, Gracia-Sancho J, Arráez-Aybar LA, Nevzorova YA, Cubero FJ. The Space of Disse: The Liver Hub in Health and Disease. Livers. 2021;1(1):3-26.

57. Barry AE, Baldeosingh R, Lamm R, Patel K, Zhang K, Dominguez DA, et al. Hepatic Stellate Cells and Hepatocarcinogenesis. Front Cell Dev Biol. 2020;8:709.

58. Szatmari T, Otvos R, Hjerpe A, Dobra K. Syndecan-1 in Cancer: Implications for Cell Signaling, Differentiation, and Prognostication. Dis Markers. 2015;2015:796052.

59. Regos E, Karaszi K, Reszegi A, Kiss A, Schaff Z, Baghy K, et al. Syndecan-1 in Liver Diseases. Pathol Oncol Res. 2020;26(2):813-9. 
60. Onyeisi JOS, Lopes CC, Gotte M. Syndecan-4 as a Pathogenesis Factor and Therapeutic Target in Cancer. Biomolecules. 2021;11(4).

61. Couchman JR. Syndecans: proteoglycan regulators of cell-surface microdomains? Nat Rev Mol Cell Biol. 2003;4(12):926-37.

62. Fu Y, Urban DJ, Nani RR, Zhang YF, Li N, Fu H, et al. Glypican-3-Specific Antibody Drug Conjugates Targeting Hepatocellular Carcinoma. Hepatology. 2019;70(2):563-76.

63. Filmus J, Capurro M, Rast J. Glypicans. Genome Biol. 2008;9(5):224.

64. Li N, Gao W, Zhang YF, Ho M. Glypicans as Cancer Therapeutic Targets. Trends Cancer. 2018;4(11):741-54.

65. Ramani VC, Purushothaman A, Stewart MD, Thompson CA, Vlodavsky I, Au JL, et al. The heparanase/syndecan-1 axis in cancer: mechanisms and therapies. FEBS J. 2013;280(10):2294-306.

66. Bukong TN, Maurice SB, Chahal B, Schaeffer DF, Winwood PJ. Versican: a novel modulator of hepatic fibrosis. Lab Invest. 2016;96(3):361-74.

67. Dhar D, Antonucci L, Nakagawa H, Kim JY, Glitzner E, Caruso S, et al. Liver Cancer Initiation Requires p53 Inhibition by CD44-Enhanced Growth Factor Signaling. Cancer Cell. 2018;33(6):1061-77 e6.

\section{Figure Legends}

Figure 1. CSGALNACT1 is dramatically up-regulated in FLC. (A) A schematic showing the sequence of events leading to heparan and chondroitin synthesis. (B) Differential expression of EXTL2, EXT1, EXT2, and NDST1 is shown as normalized counts in FLC $(n=23)$ and NML $(n=4)$. (C) Differential expression of CSGALNACT1, CSGALNACT2, CHPF, and CHSY1 is shown as normalized counts in FLC $(\mathrm{n}=23)$ and NML $(\mathrm{n}=4)$. (D) CSGALNACT1 expression relative to EXTL2 expression is shown as a ratio of normalized counts in FLC ( $n=23)$ and NML ( $n=4)$. (E) Quantitative PCR showing the relative quantitative value (RQV) of CSGALNACT1 in a separate cohort of FLC samples $(n=11)$ compared to NML samples $(n=5)$. (F) Quantitative PCR showing the relative quantitative value (RQV) of CSGALNACT1 in a subset of FLC samples $(n=4)$ that have matched NML tissue. The matched NML/FLC samples are indicated with a line linking the two data points. ${ }^{*} P<0.05,{ }^{* *} P<0.01,{ }^{* *} P<0.001$, two-tailed Student's t-test.

Figure 2. Chondroitin sulfate disaccharide abundance is significantly increased in FLC. (A) A schematic diagram detailing disaccharide extraction and identification. (B) Nanograms of chondroitin sulfate (CS) per milligram of dry tissue in FLC $(n=11)$ and NML $(n=5)$ tissue. (C) Nanograms of non-sulfated chondroitin sulfate (CS di-0S) per milligram of dry tissue in FLC $(n=11)$ and NML $(n=5)$ tissue. (E) Nanograms of heparan sulfate (HS) per milligram of dry tissue in FLC $(n=4)$ and NML $(n=2)$ tissue. ${ }^{*} P<0.05$, two-tailed Student's t-test. 
Figure 3. Monosulfated chondroitin sulfate disaccharide abundance is significantly increased in FLC.

(A) A schematic diagram detailing CS di-4S. (B) Differential expression of CHST11 is shown as normalized counts in FLC $(n=23)$ and NML $(n=4)$. (C) Nanograms of CS di-4S per milligram of dry tissue in FLC $(n=11)$ and NML ( $n=5$ ) tissue. (D) A schematic diagram detailing CS di-6S. (E) Differential expression of CHST3 is shown as normalized counts in FLC $(n=23)$ and NML $(n=4)$. (F) Nanograms of CS di-6S per milligram of dry tissue in FLC ( $n=11)$ and NML $(n=5)$ tissue. (G) A schematic diagram detailing CS di-4S6S. (H) Differential expression of CHST15 is shown as normalized counts in FLC $(n=23)$ and NML $(n=4)$. (I) Nanograms of CS di4S6S per milligram of dry tissue in FLC $(n=11)$ and NML $(n=5)$ tissue. (J) A schematic diagram detailing CS di2S4S. (K) Differential expression of UST is shown as normalized counts in FLC $(n=23)$ and NML $(n=4)$. (L) Nanograms of CS di-2S4S per milligram of dry tissue in FLC $(n=11)$ and NML $(n=5)$ tissue. * $P<0.05$, two-tailed Student's t-test.

Figure 4. Chondroitin sulfate associated protein VCAN is aberrant in FLC. (A) Differential expression of VCAN, CD44, and CSPG4 is shown as normalized counts in FLC $(\mathrm{n}=23)$ and NML $(\mathrm{n}=4)$. (B) Quantitative PCR showing the relative quantitative value (RQV) of VCAN in a separate cohort of FLC samples $(n=11)$ compared to NML samples ( $n=5)$. (C) Quantitative PCR showing the relative quantitative value (RQV) of VCAN in a subset of FLC samples that have matched NML tissue $(n=4)$. The matched NML/FLC samples are indicated with a line linking the two data points. (D) Immunoblot in matched FLC/NML samples $(n=3)$ showing VCAN in the lower and vinculin in the upper panel. (E) VCAN protein levels normalized to vinculin levels are shown as relative quantitative value $(\mathrm{RQV})$. The matched NML/FLC samples are indicated with a line linking the two data points. (F) IHF of VCAN protein in two independent patient-matched tissue samples is shown in green. Nuclei are blue. Scale bar equals $100 \mu \mathrm{m} .{ }^{*} P<0.05,{ }^{* *} P<0.01,{ }^{* *} P<0.001$, two-tailed Student's t-test.

Figure 5. CSGALNACT1 and VCAN are more highly up-regulated in FLC than in almost all other cancers and correlate with DNAJB1-PRKACA levels. (A) Normalized counts of CSGALNACT1 expression in RNA-seq data sets available for 25 tumor types in The Cancer Genome Atlas (TCGA). (B) Normalized counts of VCAN expression in RNA-seq data sets available for 25 tumor types in The Cancer Genome Atlas 
(TCGA). (C) Correlation between CSGALNACT1 (y-axis) and VCAN (x-axis) shown as the log of normalized

counts in FLC samples ( $\mathrm{n}=27$ ). (D) Correlation between CSGALNACT1 (y-axis) and VCAN (x-axis) shown as the relative quantitative values from $\mathrm{qPCR}$ in a separate cohort of FLC samples $(n=11)$. (E) Correlation between DNAJB1-PRKACA (y-axis) and VCAN (x-axis) shown as the relative quantitative values from RTqPCR in FLC samples ( $\mathrm{n}=11)$. (F) Correlation between DNAJB1-PRKACA (y-axis) to CSGALNACT1 (x-axis) shown as the relative quantitative values from RT-qPCR in FLC samples $(n=11)$. ACC, adenoid cystic carcinoma; BLCA, bladder urothelial carcinoma; BRCA, breast invasive carcinoma; CESC, cervical squamous cell and endocervical adenocarcinoma; CHOL, cholangiocarcinoma; COAD, colon adenocarcinoma; DLBC, diffuse large B-cell lymphoma; ESCA, esophageal carcinoma; FCL, fibrolamellar carcinoma samples analyzed in this study; GBM, glioblastoma; HNSC, head and neck squamous cell carcinoma; $\mathrm{KICH}$, kidney chromophobe; KIRC, kidney renal papillary cell carcinoma; KIRP, kidney renal clear cell carcinoma; LAML, acute myeloid leukemia; LGG, lower grade glioma; LIHC, liver hepatocellular carcinoma; LUAD, lung adenocarcinoma; LUSC, lung squamous cell carcinoma; MESO, mesothelioma; PAAD, pancreatic adenocarcinoma; PCPG, pheochromocytoma and paraganglioma; PRAD, prostate adenocarcinoma; READ, rectum adenocarcinoma; SARC, sarcoma; SKCM, skin cutaneous melanoma; STAD, stomach adenocarcinoma; TGCT, testicular germ cell tumor; THCA, thyroid carcinoma; THYM, thymoma; UCEC, uterine corpus endometrial carcinoma; UCS, uterine carcinosarcoma; UVM, uveal melanoma.

\section{Figure 6. Activity at the VCAN locus is high in both tumor epithelial and activated stellate cells in FLC.}

(A) UMAP dimensional reduction showing eight cell clusters found in primary FLC, metastatic FLC, and NML tissue ( 9,500 nuclei). (B) Single-cell analysis of chromatin accessibility near the CSGALNACT1 locus. Increasing signal is indicated by the color gradient (maximum signal is yellow and minimal signal is dark blue). (C) Genome tracks showing the location of open chromatin near the CSGALNACT1 locus in each cell type. The annotated transcriptional start site for CSGALNACT1 is shown at the bottom of the panel. (D) Single-cell analysis of chromatin accessibility near the VCAN locus. Increasing signal is indicated by the color gradient (maximum signal is yellow and the minimal signal is dark blue). (E) Genome tracks showing the location of open chromatin signal near the VCAN locus in each cell type. The annotated transcriptional start site for VCAN 
is shown at the bottom of the panel. Cell clusters are denoted through color-coding: NML hepatocytes in light blue, FLC primary tumor transformed epithelial cells in orange, FLC metastatic tumor transformed epithelial cells in red, NML cholangiocytes in yellow, FLC primary and metastatic activated stellate cells in dark blue, FLC primary and metastatic immune cells in dark purple, FLC primary and metastatic endothelial cells in green, and NML immune and endothelial cells in light purple.

Figure 7. Model for the relevance of chondroitin sulfate and versican in FLC. A schematic showing the behaviors of non-malignant hepatocytes, quiescent and activated stellate cells, and endothelial cells with respect to chondroitin sulfate and versican during FLC progression.

Supplemental Figure 1. Quantification of chondroitin sulfate disaccharides. (A) Schematic of preparation of ${ }^{13} \mathrm{C}$-labeled CS disaccharides. Four ${ }^{13} \mathrm{C}$-labeled CS disaccharide calibrants were prepared from chondroitin ABCase digestion of three ${ }^{13} \mathrm{C}$-labeled 8-mers. The disaccharides were purified to homogeneity after a QSepharose column purification. The ${ }^{13} \mathrm{C}$-labeled carbon atoms in the DUA residue are indicated with blue dots. pNP represents p-nitrophenyl. (B) The curve and linear equation of normalized peak area as a function of concentration for $\Delta$ di-0S are shown. The concentration of $\Delta$ di-0S used for LC-MS/MS analysis were 0.125 , $0.313,0.625,1.25,3.13,6.25,12.5,25,50$ and $100 \mu \mathrm{g} / \mathrm{mL}$, mixing with $0.8 \mu \mathrm{g} / \mathrm{mL}$ disaccharide calibrant $\Delta$ di4S. Data represent means \pm S.D. $(n=3)$ (C) The curve and linear equation of normalized peak area as a function of concentration for $\Delta \mathrm{di}-4 \mathrm{~S}$ are shown. The concentration of $\Delta \mathrm{di}-4 \mathrm{~S}$ used for LC-MS/MS analysis were $0.125,0.313,0.625,1.25,3.13,6.25,12.5,25,50$ and $100 \mu \mathrm{g} / \mathrm{mL}$, mixing with $4 \mu \mathrm{g} / \mathrm{mL}$ disaccharide calibrant $\Delta$ di-4S. Data represent means \pm S.D. $(n=3)(D)$ The curve and linear equation of normalized peak area as a function of concentration for $\Delta$ di-6S are shown. The concentration of $\Delta$ di-6S used for LC-MS/MS analysis were $0.125,0.313,0.625,1.25,3.13,6.25,12.5,25,50$ and $100 \mu \mathrm{g} / \mathrm{mL}$, mixing with $4 \mu \mathrm{g} / \mathrm{mL}$ disaccharide calibrant $\Delta$ di-6S. Data represent means \pm S.D. $(n=3)(E)$ The curve and linear equation of normalized peak area as a function of concentration for $\Delta \mathrm{di}-4 \mathrm{~S} 6 \mathrm{~S}$ are shown. The concentration of $\Delta \mathrm{di}-4 \mathrm{~S} 6 \mathrm{~S}$ used for LC-MS/MS analysis were $0.125,0.313,0.625,1.25,3.13,6.25,12.5,25,50$ and $100 \mu \mathrm{g} / \mathrm{mL}$, mixing with $4 \mu \mathrm{g} / \mathrm{mL}$ disaccharide calibrant $\Delta$ di-4S6S. Data represent means \pm S.D. $(n=3)$ 
Supplemental Figure 2. Quantification of heparan sulfate disaccharides. (A) Nanograms of HS $\triangle U A 2 S-$

GlcNS6S $(\Delta I S)$ per milligram of dry tissue in FLC $(n=4)$ and NML $(n=2)$ tissue. (B) Nanograms of HS $\Delta U A-$

GlcNS6S ( $\triangle I I S)$ per milligram of dry tissue in FLC $(n=4)$ and NML $(n=2)$ tissue. (C) Nanograms of HS $\triangle U A$ -

GIcNS ( $\triangle I I I S)$ per milligram of dry tissue in FLC $(n=4)$ and NML $(n=2)$ tissue. (D) Nanograms of HS $\triangle U A-$

GlcNS ( $\triangle I V S)$ per milligram of dry tissue in FLC $(n=4)$ and NML $(n=2)$ tissue. (E) Nanograms of HS $\triangle U A-$

GIcNAc6S ( $\triangle I$ IA) per milligram of dry tissue in FLC $(n=4)$ and NML $(n=2)$ tissue. $(F)$ Nanograms of HS $\triangle U A 2 S-$

GIcNAc ( $\triangle I I I A)$ per milligram of dry tissue in FLC $(n=4)$ and NML $(n=2)$ tissue. (G) Nanograms of HS $\triangle U A$ -

GIcNAc ( $\triangle I V A)$ per milligram of dry tissue in FLC $(n=4)$ and NML $(n=2)$ tissue.

\section{Supplemental Figure 3. Additional gene expression analysis in FLC samples and additional VCAN}

immunoblots. (A) Quantitative PCR showing the relative quantitative value (RQV) of CHST11 in a subset of FLC samples that have matched NML tissue $(n=4)$. $(B)$ The matched NML/FLC samples are indicated with a line linking the two data points. (C) Quantitative PCR showing the relative quantitative value (RQV) of CHST3 in a subset of FLC samples included in this study $(n=11)$ compared to NML samples ( $n=5)$. (D) Quantitative PCR showing the relative quantitative value (RQV) of CHST3 in a subset of FLC samples that have matched NML tissue $(n=4)$. The matched NML/FLC samples are indicated with a line linking the two data points. (E) Short and (F) long exposure VCAN immunoblot from Figure 4D shown in entirety. Vinculin and versican protein are denoted with arrows and molecular weight standards are denoted by dashes. Samples are labeled at the bottom of the panel. The short exposure blot was used for quantification in Figure 4E. * $P<0.05$, two-tailed Student's t-test.

Supplemental Figure 4. Marker genes of cell clusters from the single-cell ATAC data. (A) Signal intensity of chromatin accessibility near the EPCAM, PKHD1, and FGFR2 gene loci denoting cholangiocytes. (B) Signal intensity of chromatin accessibility near the TYROBP, SRGN, and C1QB gene loci denoting immune cells. (C) Signal intensity of chromatin accessibility near the NOSTRIN, PTPRB, and LDB2 gene loci denoting endothelial cells. (D) Signal intensity of chromatin accessibility near the CTGF, ACTA2, and CALD1 gene loci 
denoting stellate cells. Increasing signal is indicated by the color gradient (maximum signal is yellow and minimal signal is dark blue).

\section{Supplemental Figure 5. Identification of cells that are likely positive for the signature deletion event in}

FLC. (A) Signal intensity of chromatin accessibility near the ADGRL1 gene locus. (B) Genome tracks showing the location of open chromatin signal near the $A D G R L 1$ locus in each cell type. The annotated transcriptional start site for $A D G R L 1$ is shown at the bottom of the panel.

\section{Figures}


Figure 1

A
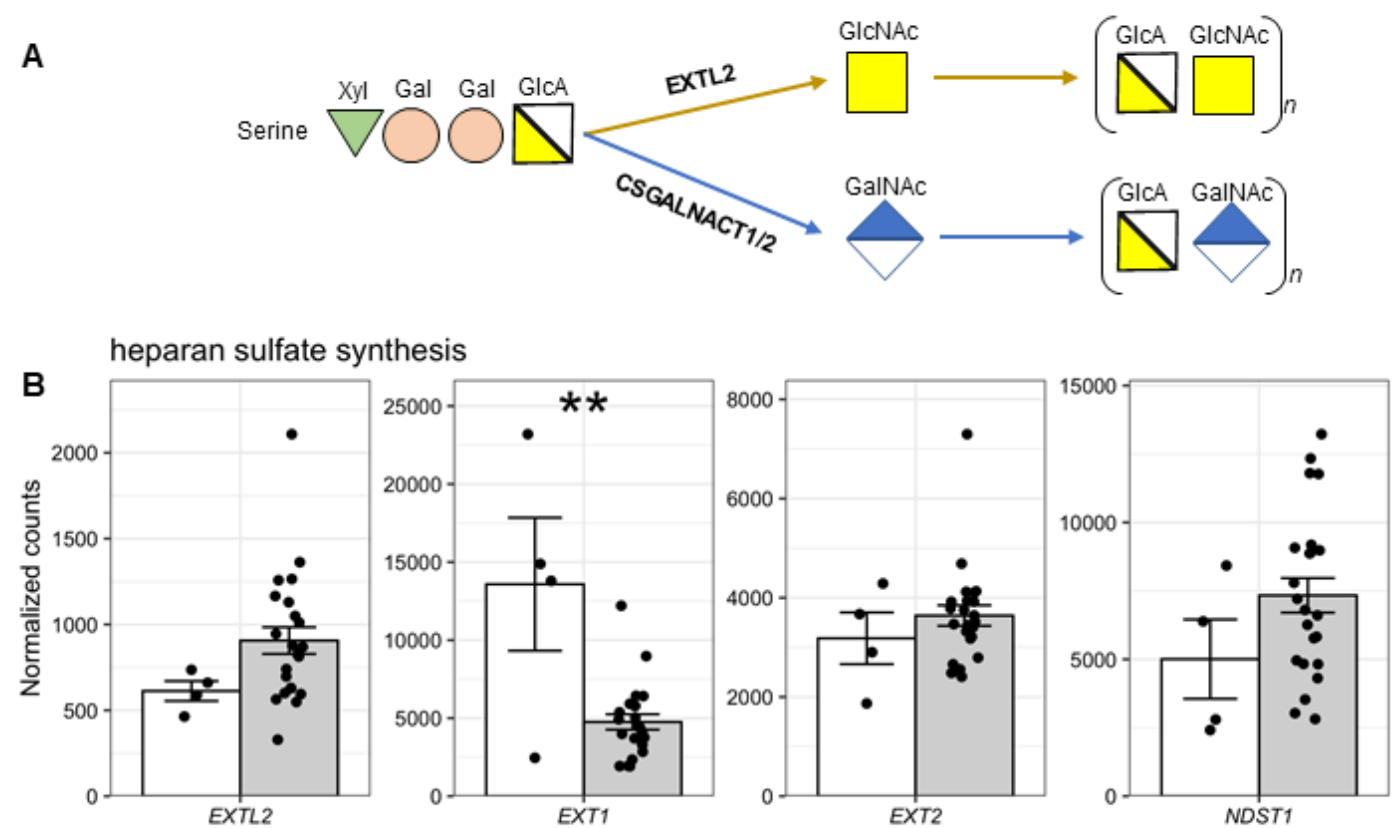

\begin{tabular}{|l|l|l}
$\bullet$ & NML \\
\hline$\bullet$ & FLC
\end{tabular}
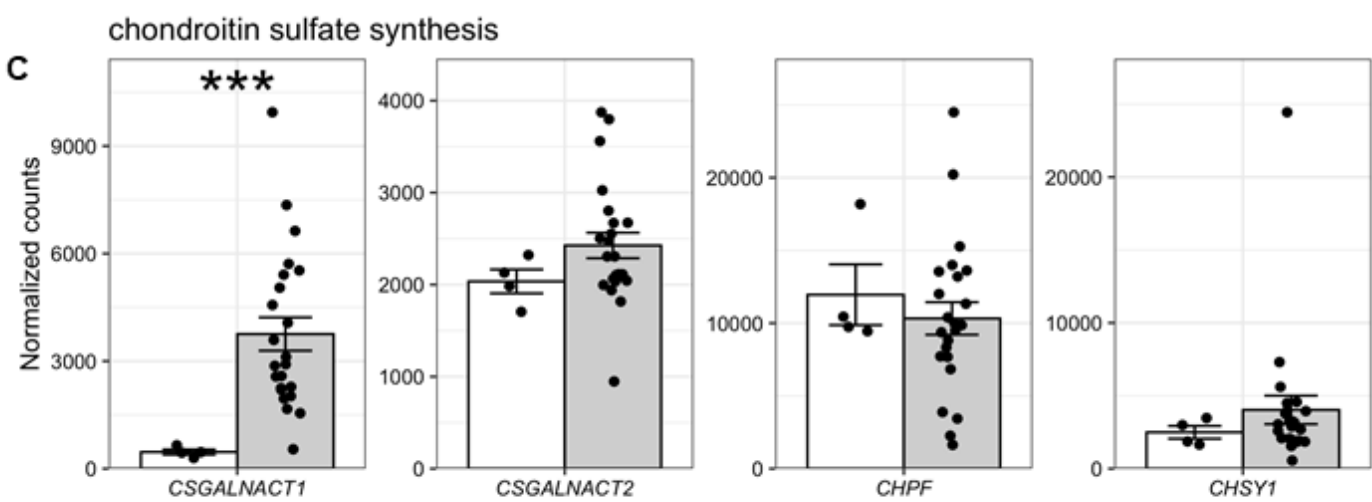

\begin{tabular}{|l|l|l|l}
\hline & NML \\
\hline- & FLC
\end{tabular}
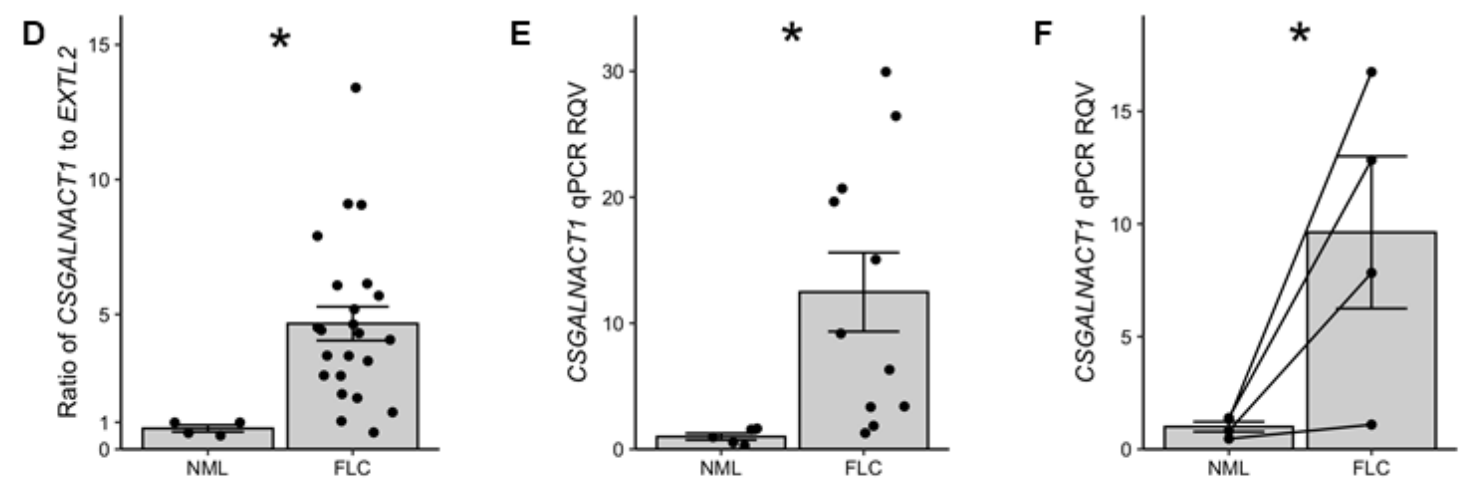


\section{Figure 2}

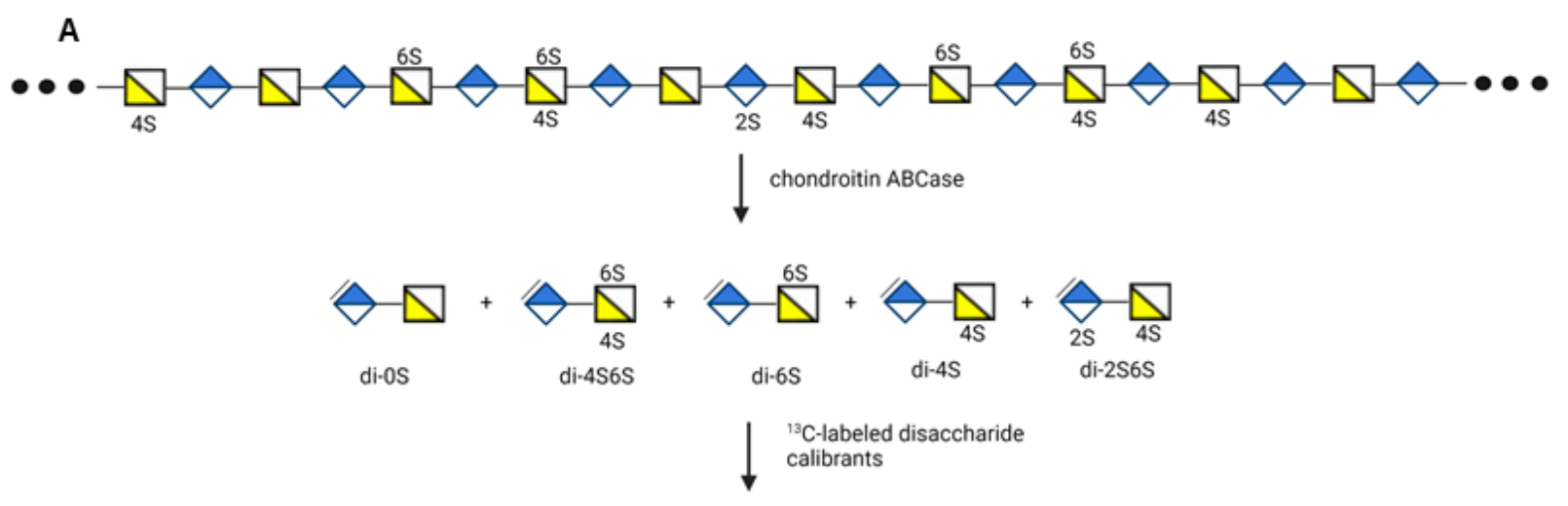

LC-MS/MS analysis
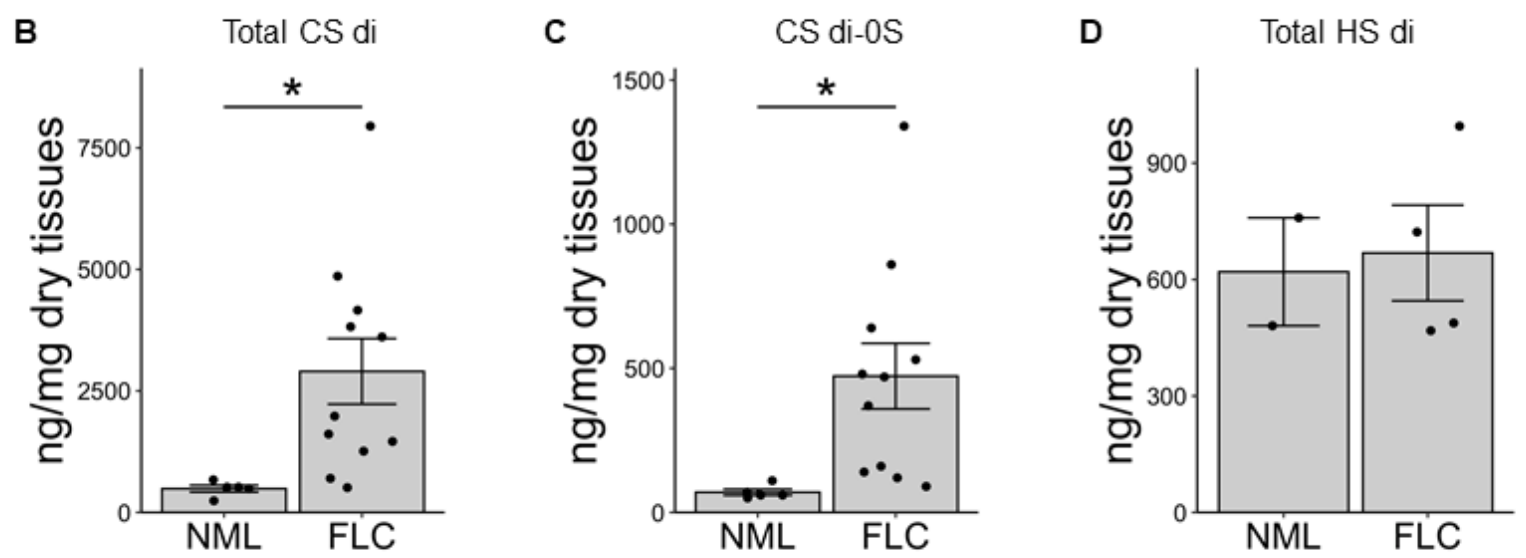


\section{Figure 3}

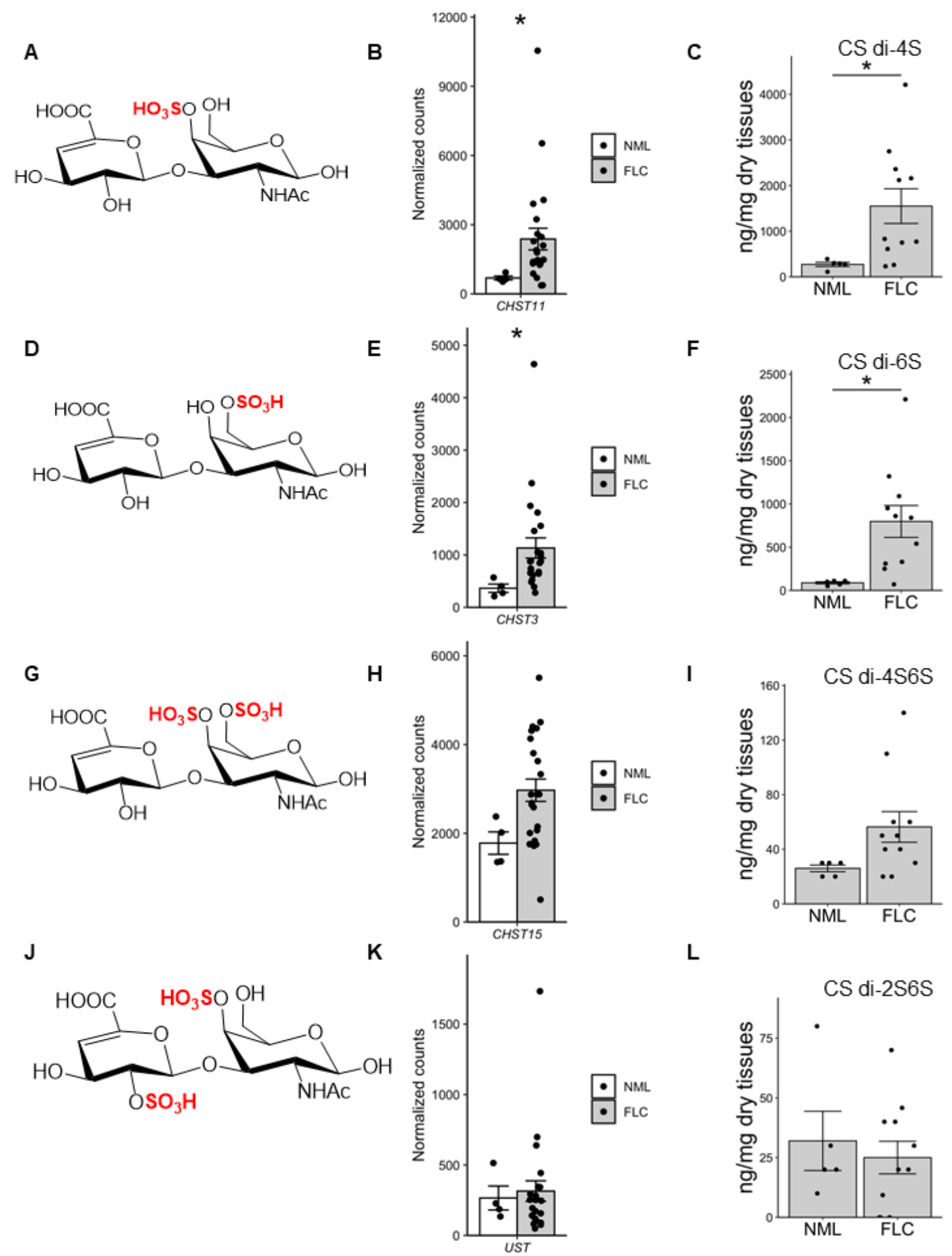




\section{Figure 4}
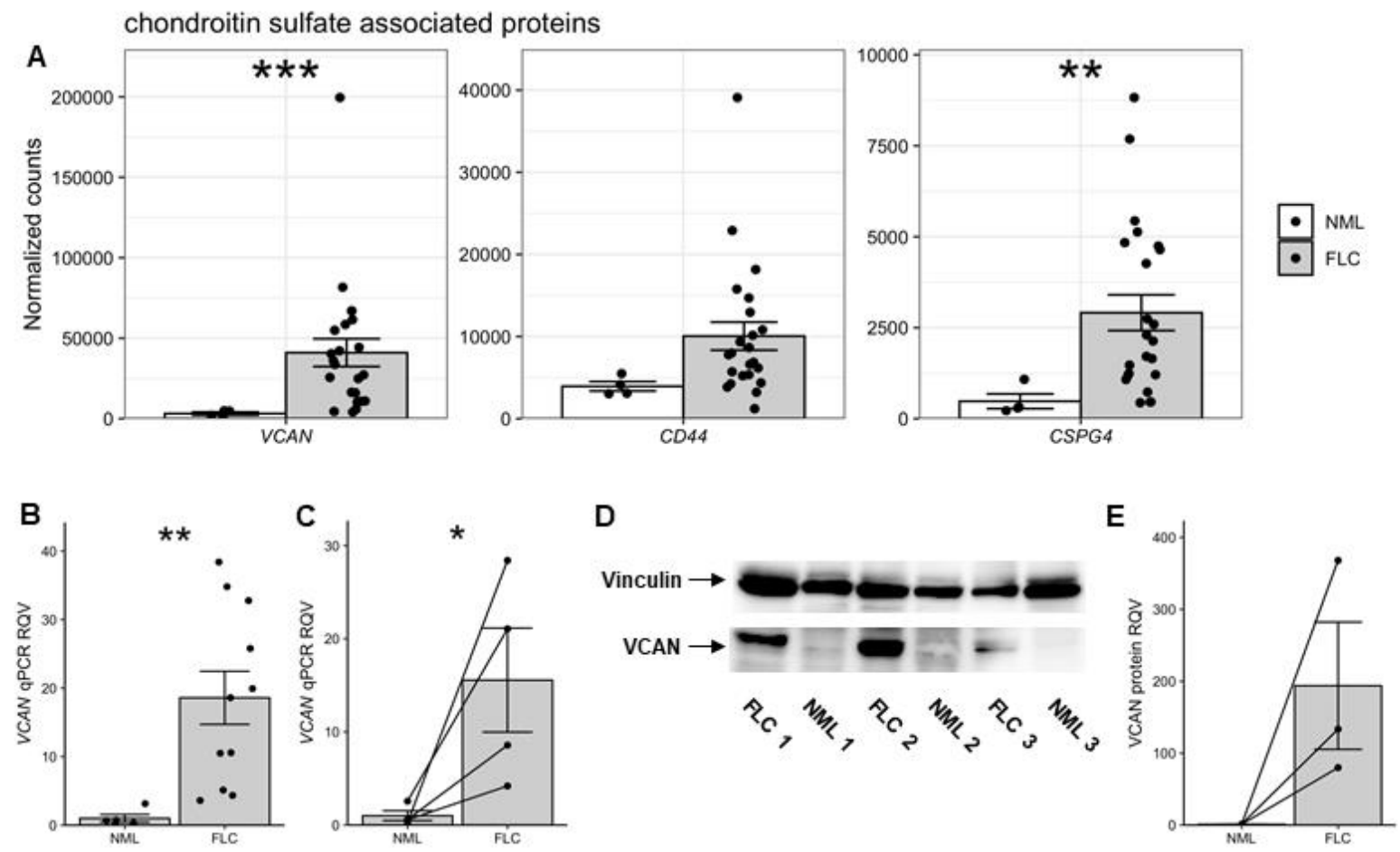

F

NML

FLC

Patient 4
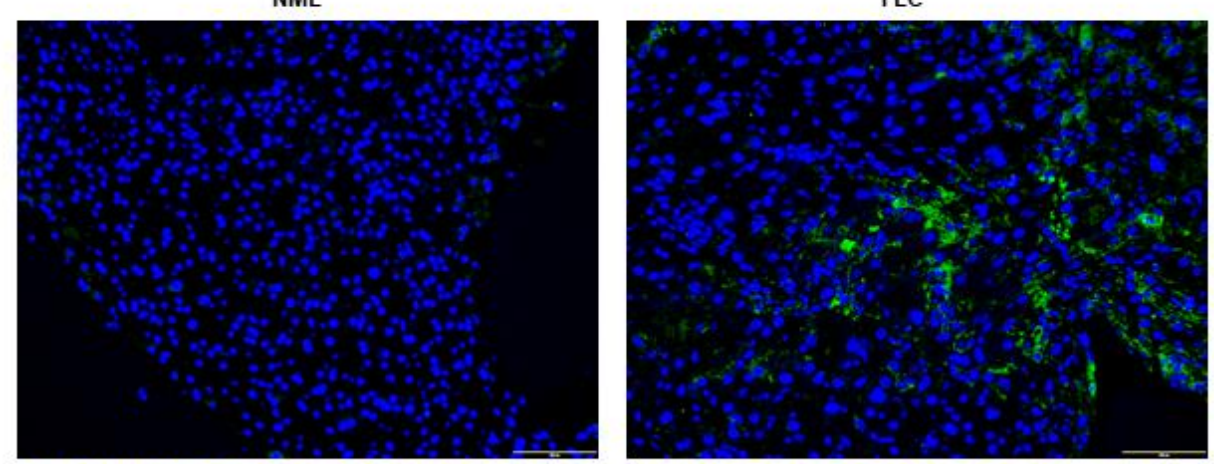

Patient 5

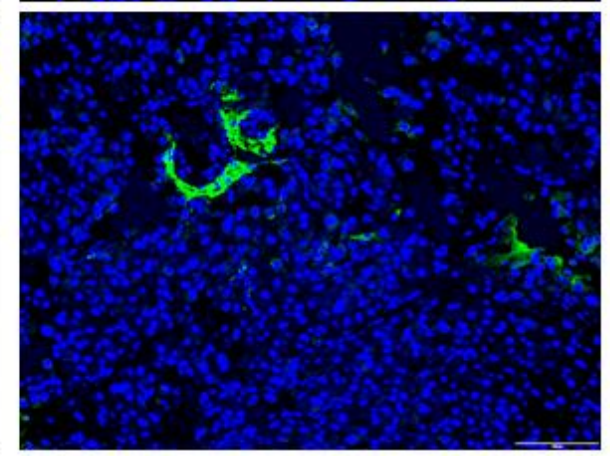




\section{Figure 5}

A

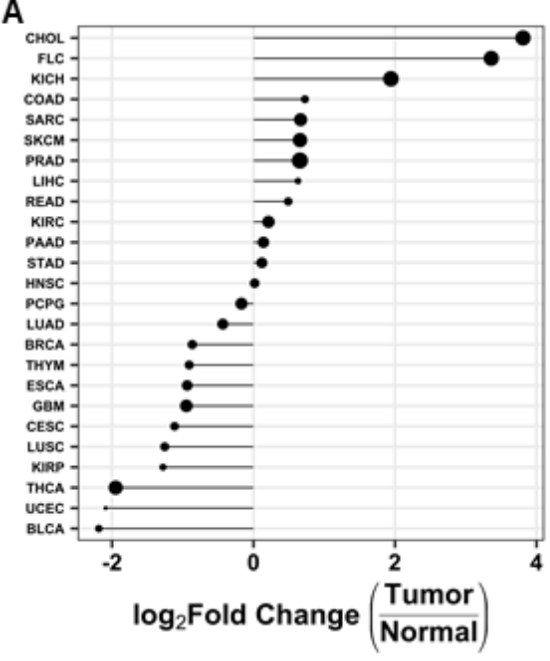

C

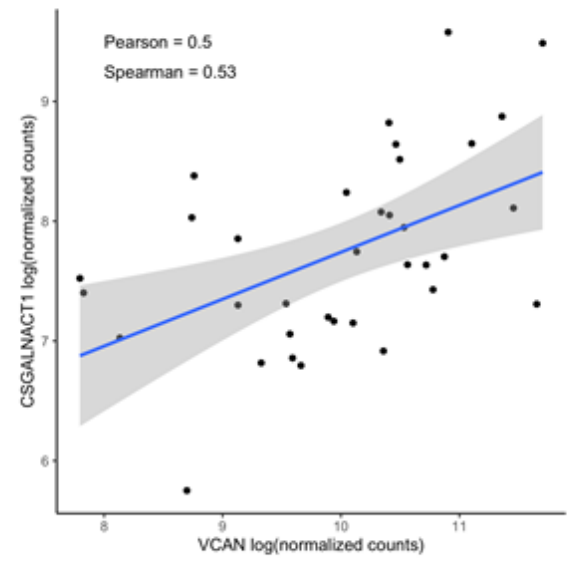

E

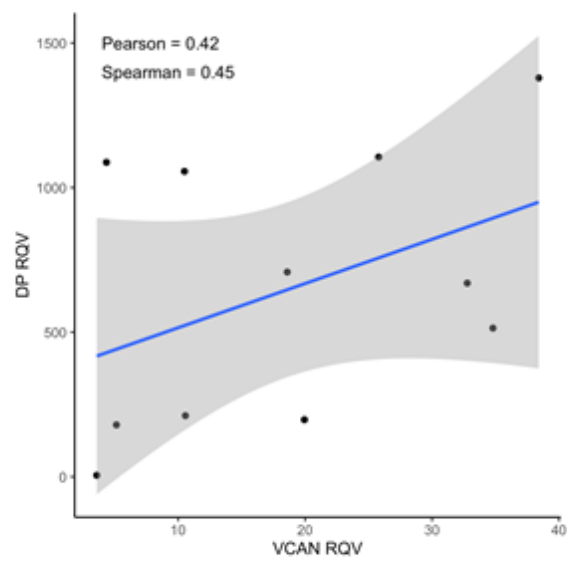

B

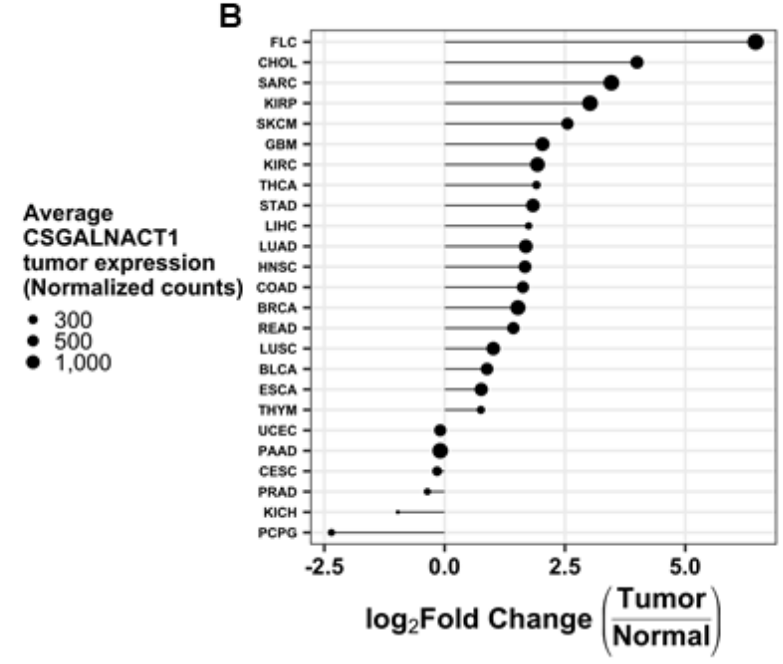

Average

VCAN

tumor expression

(Normalized counts)

: 1,000

: 10,000
D

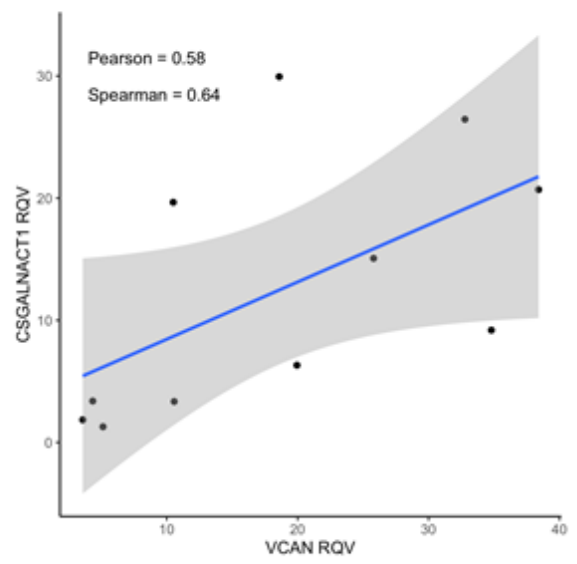

F

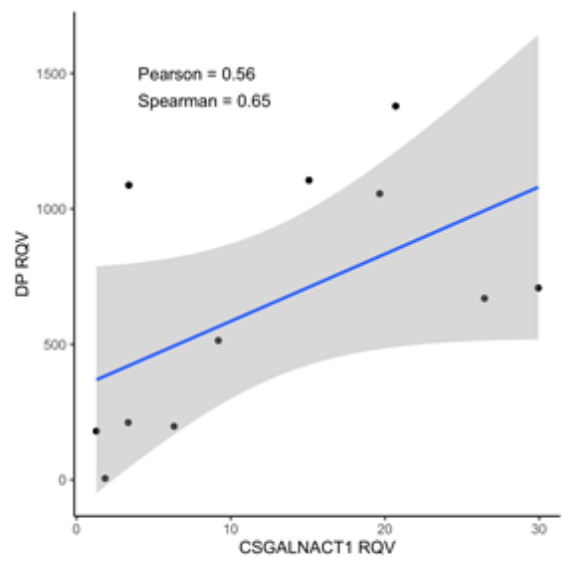


bioRxiv preprint doi: https://doi.org/10.1101/2021.12.07.471610; this version posted December 18, 2021. The copyright holder for this preprint (which was not certified by peer review) is the author/funder. All rights reserved. No reuse allowed without permission.

\section{Figure 6}

A UMAPHarmony of Harmony colored by colData: Clusters2

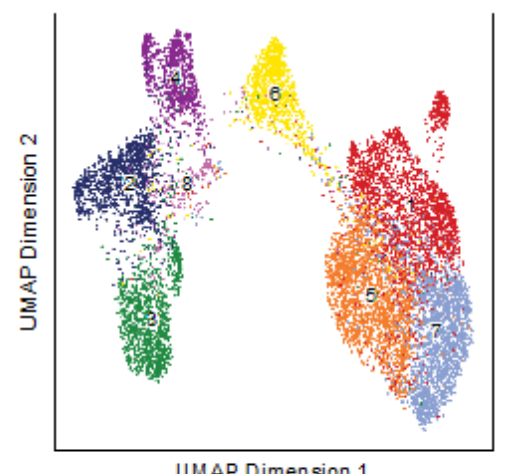

UMAP Dimension 1

B

UMAPHarmony of Harmony colored by GeneScoreMatrix : CSGALNACT1

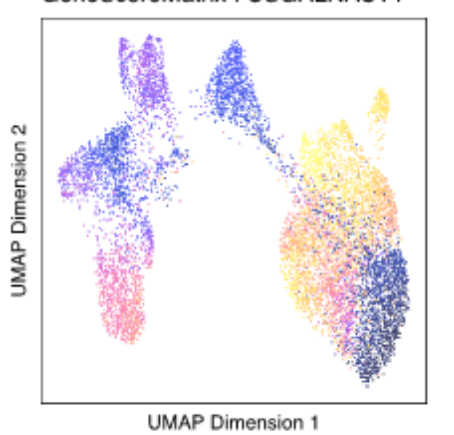

$\log 2$ (NormCounts + 1)

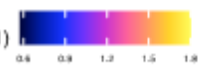

UMAPHarmony of Harmony colored by

D

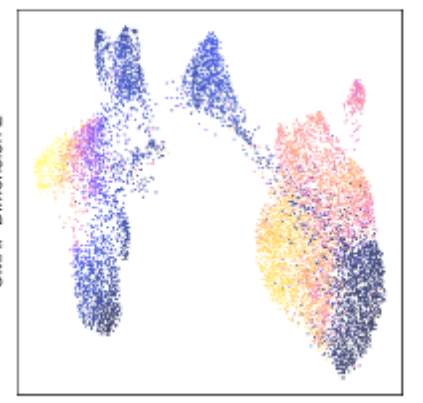

UMAP Dimension 1

$\log 2$ (NormCounts +1 )

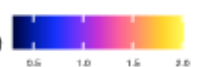

FLC-Met Transformed Epithelial

FLC-Pri and FLC-Met Activated Stellate Cells

3 FLC Endothelial cells

FLC Immune cells

5 FLC-Pri Transformed Epithelial

6 NML Cholangiocytes

7 NML Epithelial

8 NML Immune/Endothelial cells

C
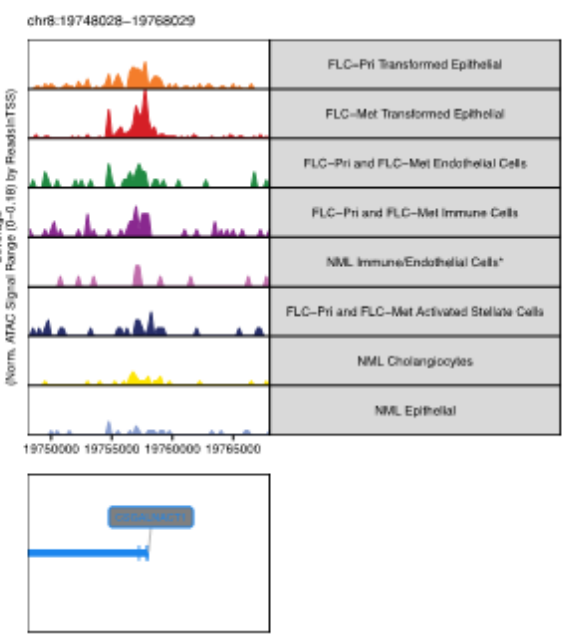

E
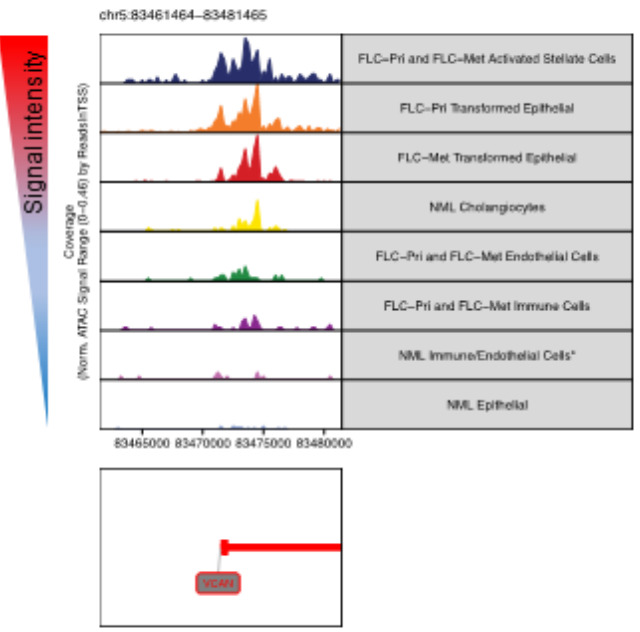
bioRxiv preprint doi: https://doi.org/10.1101/2021.12.07.471610; this version posted December 18, 2021. The copyright holder for this preprint (which was not certified by peer review) is the author/funder. All rights reserved. No reuse allowed without permission.

\section{Figure 7}

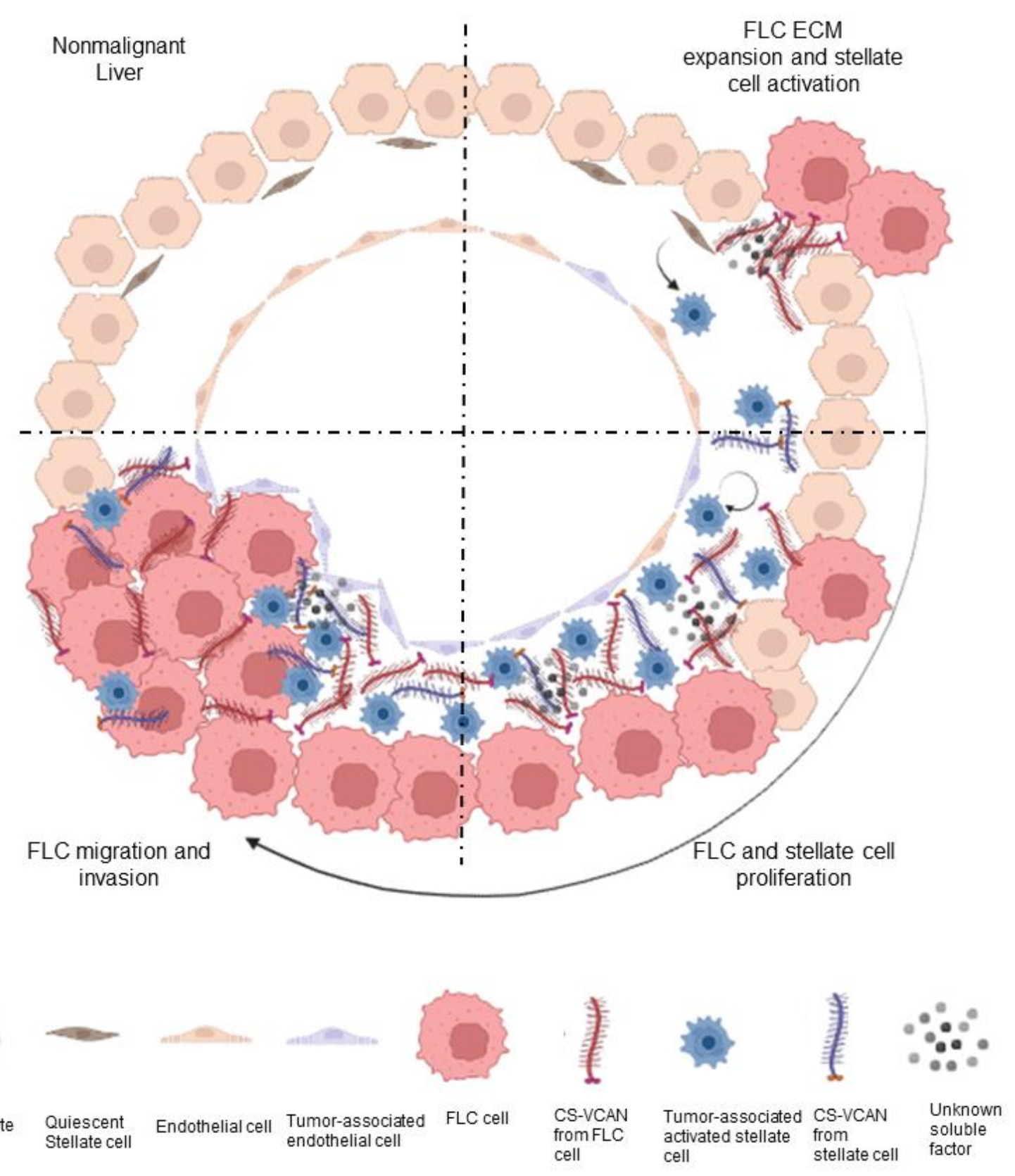




\section{Supplemental Figure 1}
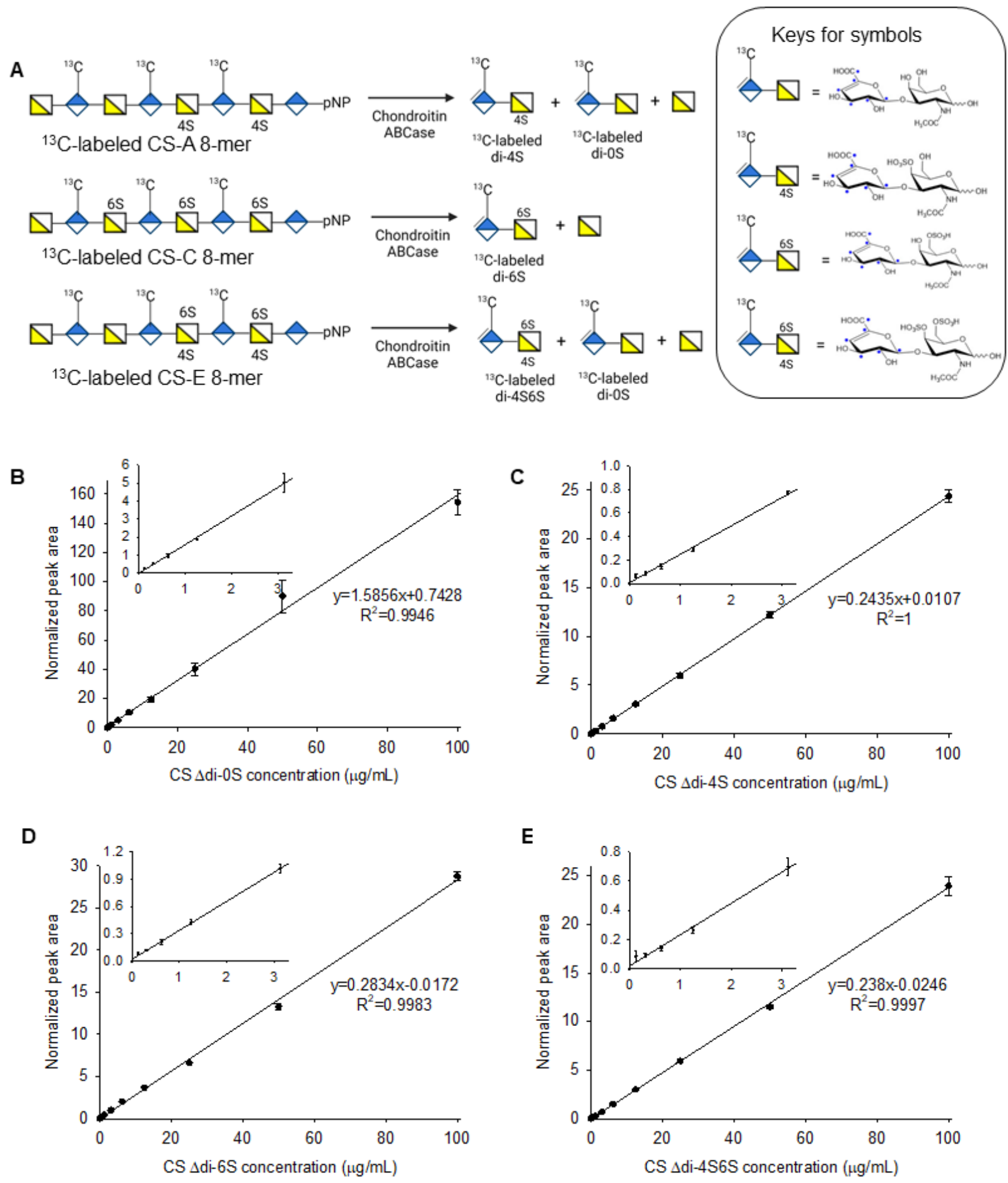


\section{Supplemental Figure 2}

A

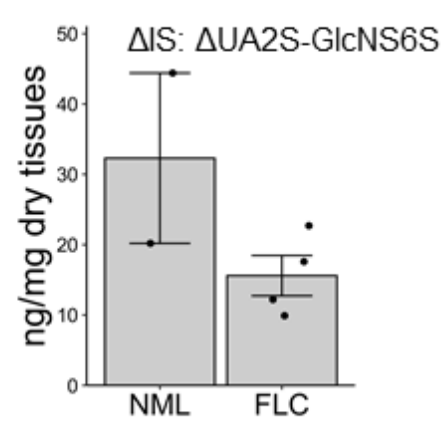

C

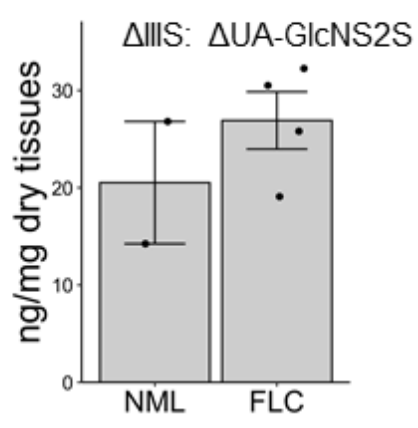

E

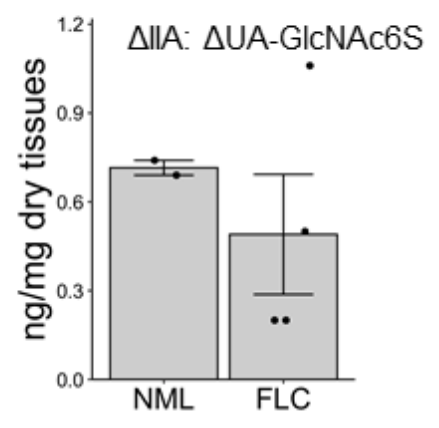

G

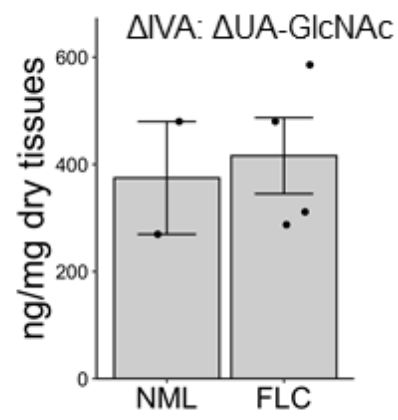

B

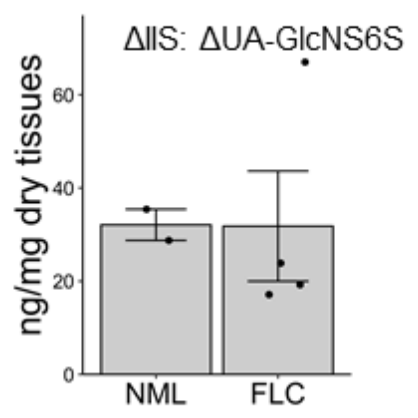

D

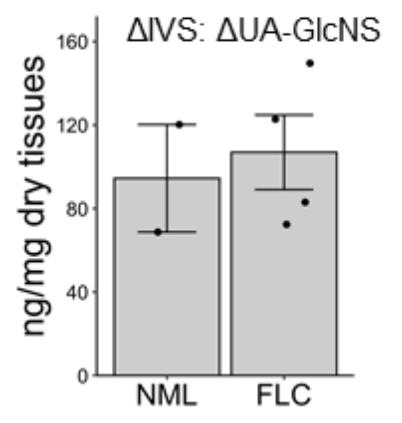

$\mathbf{F}$

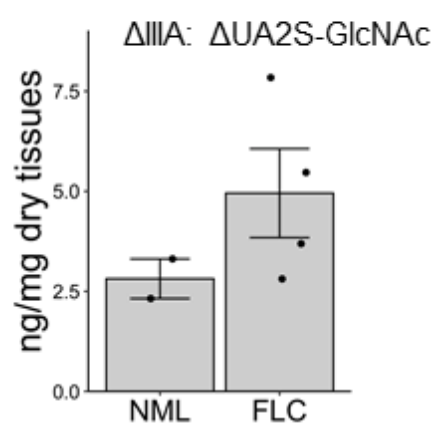




\section{Supplemental Figure 3}

A

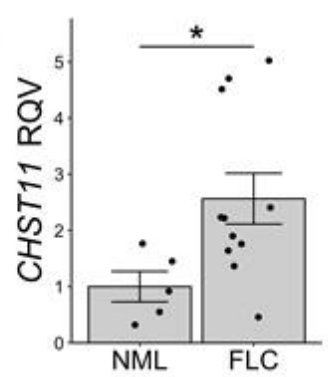

E
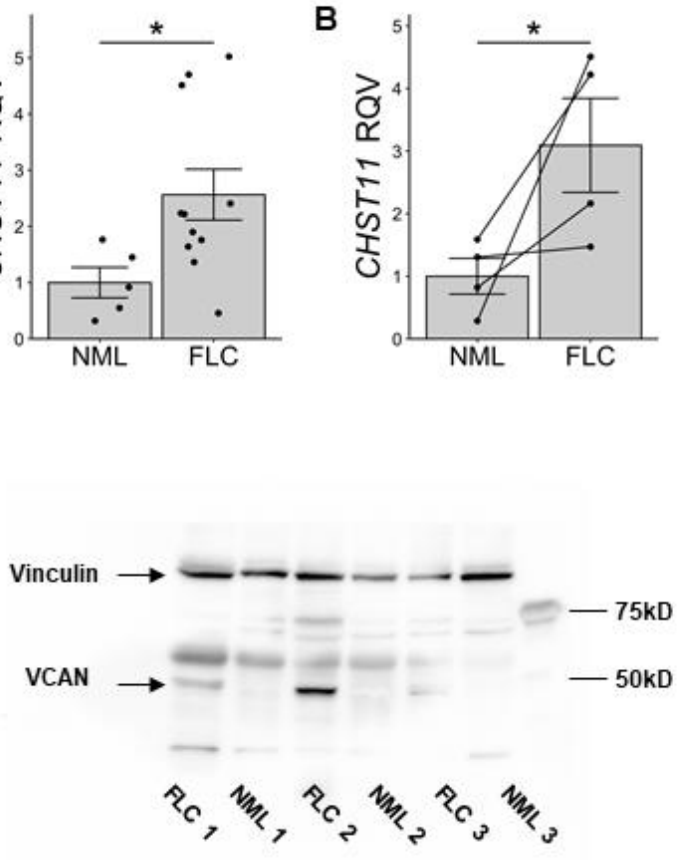

C

$\mathbf{F}$

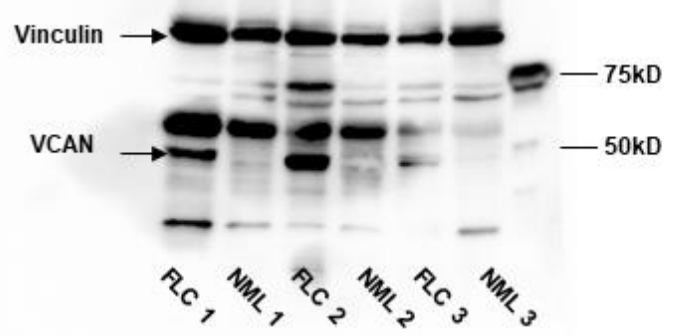


bioRxiv preprint doi: https://doi.org/10.1101/2021.12.07.471610; this version posted December 18, 2021. The copyright holder for this preprint (which was not certified by peer review) is the author/funder. All rights reserved. No reuse allowed without permission.

\section{Supplemental Figure 4}

A

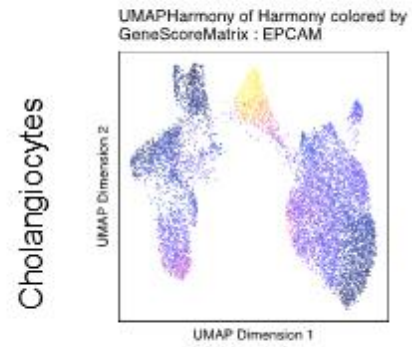

B

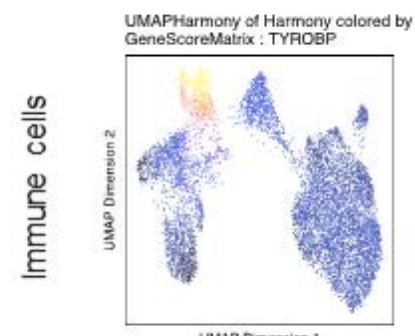

Leg21Nonricounts * 1)

C

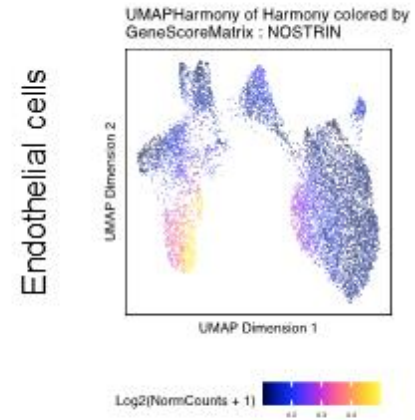

D

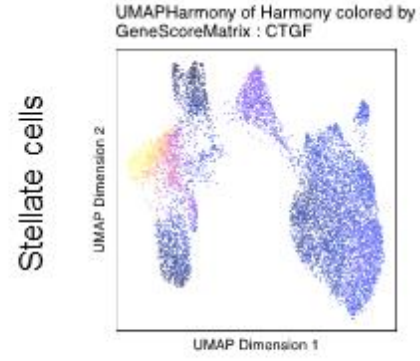

Log2iNamCounts +1
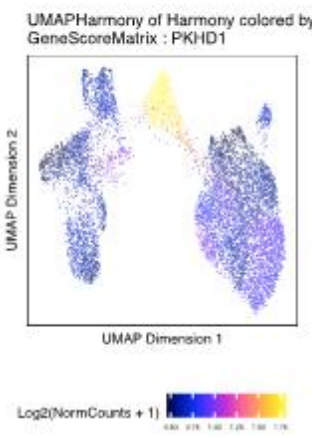

UMAPHarmony of Harmony colored by

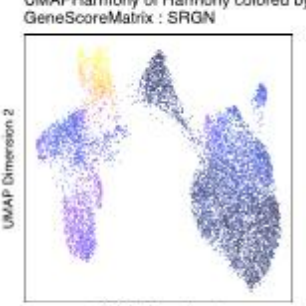

UMAP Dimension 1

Log2|Nomcounts , 1

UMAPHarmony of Harmony colored by

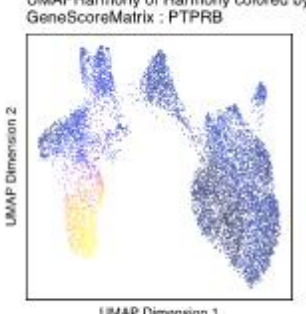

Log2iNomincouns +1

UMAPHarmony of Harmony colored by

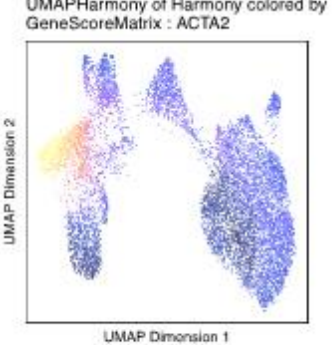

UMAP Dimonsion 1

LogapinormCounts + 1)

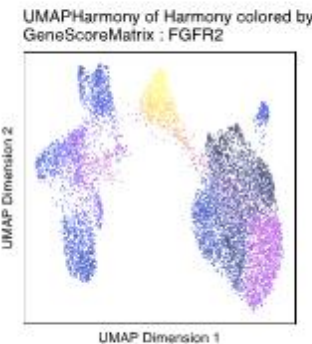

LogelNormcounts + 11

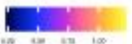

UMAPHarmony of Harmony colored by

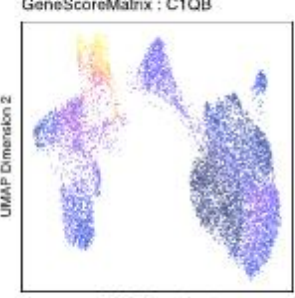

UMAP Omension 1

LogainamCounts + 1

UMAPHarmony of Harmony colored by GeneScoreMatrix : LDB2

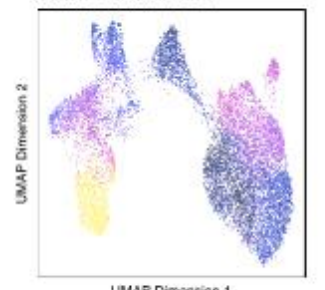

Log2/NormCounts t in

UMAPHarmony of Harmony colored by GeneScoreMatrix: CALD1

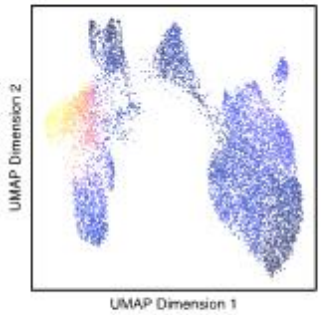

Log2(NormCounts + 1) 
bioRxiv preprint doi: https://doi.org/10.1101/2021.12.07.471610; this version posted December 18, 2021. The copyright holder for this preprint (which was not certified by peer review) is the author/funder. All rights reserved. No reuse allowed without permission.

\section{Supplemental Figure 5}

UMAPHarmony of Harmony colored by GeneScoreMatrix : ADGRL1

A

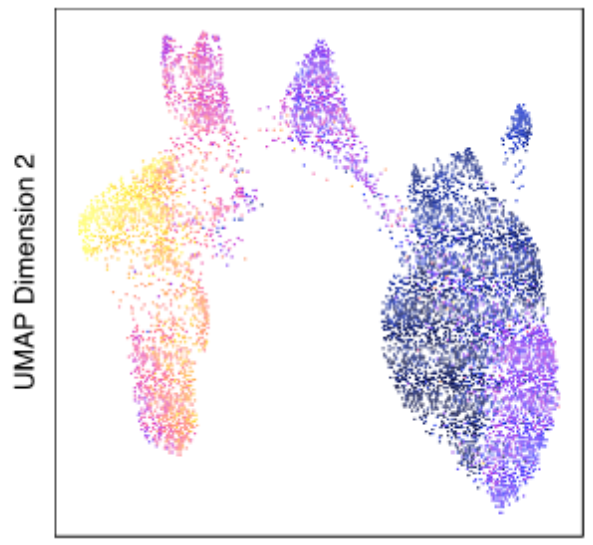

UMAP Dimension 1

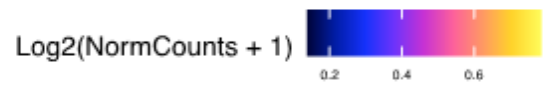

B

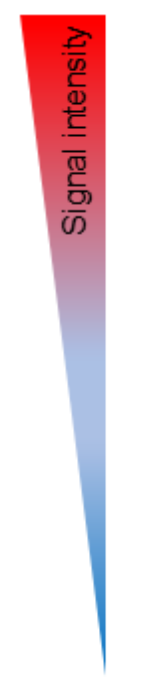

chr19:14196186-14216187
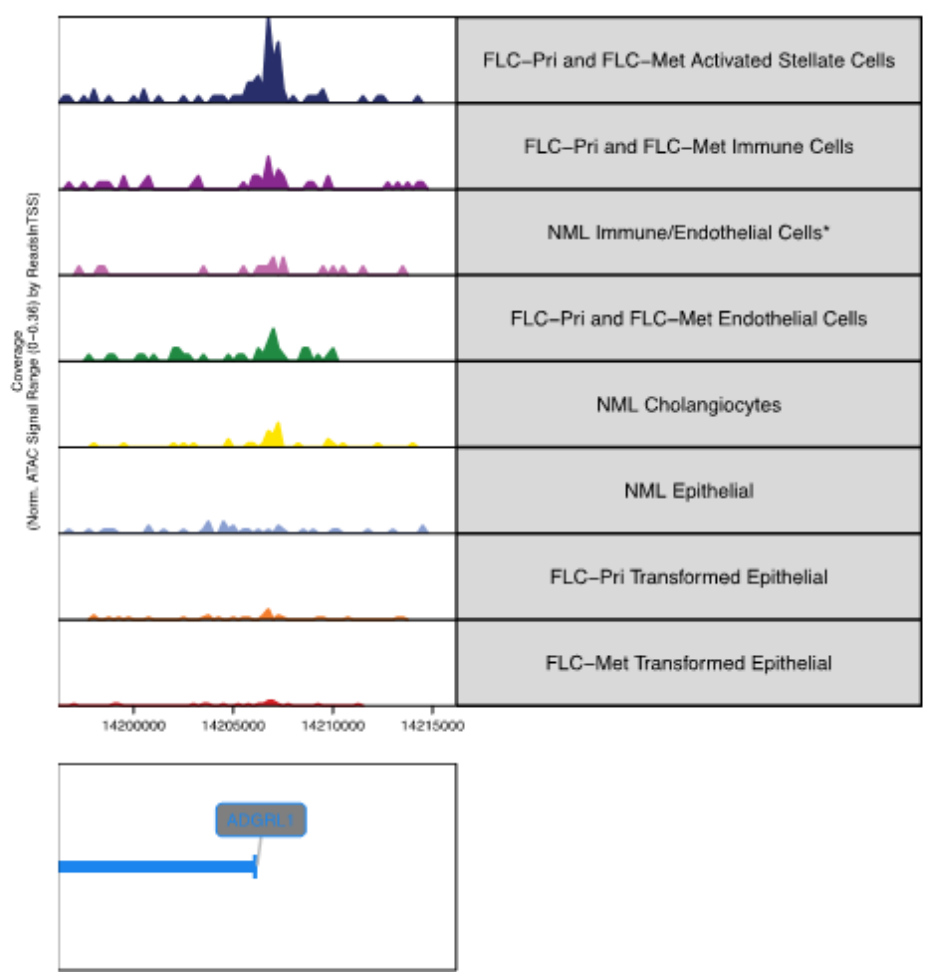